\title{
SOME MEDIEVAL AND POST-GOLDEN HORDE'S TOWNS OF THE ITIL (VOLGA) AND SYR-DARYA BASINS ACCORDING TO THE ARABIC AND CHINESE MAPS
}

\author{
Nurlan Kenzheakhmet ${ }^{1}$, Alpamys Abu $^{2}$ \\ ${ }^{1}$ Abai Kazakh National Pedagogical University \\ Almaty, Kazakhstan \\ nurlanken@hotmail.com \\ ${ }^{2}$ al-Farabi Kazakh National University \\ Almaty, Kazakhstan \\ alpamys79@gmail.com
}

\begin{abstract}
Research objectives: The earliest depictions of the towns of the Itil (Volga) and Syr-Darya Basins in medieval cartography are found on the Idrisi map (1154). The post-Golden Horde towns in these areas are found in the Jenkinson map and the Kunyu wanguo quan tu (Map of the Ten Thousand Countries of the Earth, 1602) by Matteo Ricci. In 1772, the Qianlong neifu yutu 乾隆内府與圖 (Terrestrial Map of the Imperial Repository of Qianlong), which used modern cartographic techniques, enriched the geographic information of Central Asian countries and filled the gaps in contemporary European maps.

Research materials: Influenced by the map of Al-Idrīs̄’’ the geographic gaps and blind spots on the European maps were filled, reconstructed, and connected with the new world geographic knowledge, forming a relatively complete world map. At the end of the Ming and early Qing dynasties, a large amount of overseas geographic knowledge was introduced by Western missionaries who entered China.

Results and novelty of the research: The analysis of Arab, European, and Chinese maps made it possible to assess the degree of accuracy of their information about the postGolden Horde cities of the Itil (Volga) and Syr-Darya basins. The authors managed to determine the geographical ideas of Arab, European, and Chinese geographers about Central Asia. Specifically, this article examined the place names of the Itil Basin (including Western Siberia) and the Qazaq Steppe (including adjacent regions) in the European-Russian imperial maps and in the Qing Chinese maps. Historical maps provide rich resources of knowledge that graphically encode information about the state of a fraction of the real world at a certain point in time.
\end{abstract}

Keywords: Al-Idrīsī's Map, European maps, Qianlong neifu yutu (Terrestrial Map of the Imperial Repository of Qianlong), Itil Basin, Central Asia, Qazaq Steppe

For citation: Kenzheakhmet N., Abu A. Some Medieval and Post-Golden Horde's Towns of the Itil (Volga) and Syr-Darya Basins According to the Arabic and Chinese Maps. Zolotoordynskoe obozrenie=Golden Horde Review. 2021, vol. 9, no. 3, pp. 611-653. DOI: $10.22378 / 2313-6197.2021-9-3.611-653$

\section{The Itil (Volga) and Syr-Darya Basins' Cities on the Al-Idrīsī’s Map}

The Volga (Itil) is usually called Itil (or Atil) in Arabic [17, "Itil"]. On the AlIdrīsī's Map, place names in the Itil Basin and the "adjacent regions" provide clear evidence that the map makers drew from earlier Islamic maps and Arabic accounts 
for their geographical information. In addition to its fairly accurate contours, the Al-Idrīsī's Map demonstrates knowledge about more than ten places in the Itil Basin, and more than ten in the Syr Darya-Talas Valley. On the northern coast of Caspian several names appear on the map: Āṭ̂l, al-Bayḍā, Khamlīkh, Burțās, Sawān, Bulghār, al-Bayḍā', no nearer than 200 parasangs from Balanjar, according to al-Tabarī, the western town of the Ātil [46, p. 38-39]. According to the Arab geographers, Ātil was a double town, for it was divided by the Ātil River into a western and an eastern part, the former being the residence of the king and his army (al-Bayḍā), and the latter the commercial centre (Khamlīkh) [34, p. 452]. The ruins of this city are located along the Volga delta at the northwestern corner of the Caspian Sea.

Al-Idrīsī called the Aral Sea as Buhayrat Khwārazm. East of the Aral Sea occurs several cities, such as Ghuzzia, Khwāra, Kahand, Jājān, Asfinjab (modern Sayram in Kazakhstan), and Tarāz (modern Taraz in Kazakstan).

\section{The Al-Idrīsī's Map's Influence on the seventeenth and eighteenth centu- ries' European and Jesuit Maps}

The Kitāb Nuzhat al-mushtāq fì ikhtirāq al-āfāq (Entertainment for He Who Longs to Travel the World), composed in 549/1154 by al-Idrīisì, became the first Arabic geographical work to be printed in Europe, in 1592 [36; 21; 23, p. 104]. In the history of European maps of Central Asia, the book of Idrīsī plays a certain, though not very important, part. As Tolmacheva pointed out, Arab geography represents an important chapter in the emergence of European Orientalism at the turn of the seventeenth century. In terms of knowledge of the globe and precision in map making, European cartography was by then so far ahead of al-Idrīsì, however far ahead he had been of his contemporaries, that this resurrection of his map by a modern scholar is valuable primarily in historical terms. Although Islamic maps were of limited geographical value, they were far superior to medieval European maps $[48$, p. 141, 143, 149]. The cartographers of the seventeenth century obviously felt convinced that the book of Idirisi was of such great importance that they had to enter the names of his itinerary in one way or other.

Before the eighteenth century, Western knowledge of Siberia, Central, and Northern Asia (including Manchuria) was extremely limited. This area was known simply as "Tartary" [16, p. 625-626].

Ortelius's Tartariae sive Magni Chami Regni tÿpus, published in Latin in 1570 in Antwerpen, Duval's (1619-1683) L'Asie, printed in Paris 1664, Guillaume de L'Isle's (1675-1726) Carte de Tartarie, printed in Paris in 1706, d'Anville's Carte la plus generale et qui comprend la Chine, la Tartarie chinoise, et le Thibet, shows some al-Idrisi influence. For European cartographers like Guillaume de L'Isle, the Idrisi's work was valued for the systematic descriptions, collected from a variety of sources, of those parts of the Asian continent that were still unfamiliar to European travellers.

Notes scattered in various places around the map (all the writing is in Latin) indicate that Guillaume de L'Isle carefully consulted the text of Nuzhat al-mushtāq fi ikhtirāq al-âfāq. Virtually identical versions of the sections of "Pays des Calmoucs" of the Carte de Tartarie, are to be found on the Idrīsî̀s maps. The nomenclature is a mixture of European, often Latinized, names and transcriptions of Arabic place names. Idrīsī's map carried new information for the regions traversed 
by Islamic trade routes as well as contemporary Europe. According to David L.B. Jupp, d'Anville's Carte la plus generale et qui comprend la Chine, la Tartarie chinoise, et le Thibet includes more recent information from Central Asia and information from the Russian-backed first Bering expedition (1725-1728). Otherwise the information was obtained during the Jesuit-led Kangxi survey of 17041719 [25, p. 2]. However, the Aral Sea Basin, Talas-Chu valleys, Māwarā'an-nahr as well as some other areas west of the Xinjiang was based on information provided by Idrīsī's maps. The four maps marks the place names with legend Idrīsī, along which the following names are entered (see Table I).

Table I

\begin{tabular}{|c|c|c|c|c|c|}
\hline $\begin{array}{l}\text { al-Idrisi } \\
{[33, \mathrm{IV},} \\
87-89, \mathrm{VI}]\end{array}$ & $\begin{array}{c}\text { Ortelius's } \\
\text { Tartariae } \\
\text { sive Magni } \\
\text { Chami } \\
\text { Regni } \\
\text { tÿpus } \\
(1570)\end{array}$ & $\begin{array}{l}\text { Duval's } \\
\text { L'Asie } \\
\text { (1664) [14] }\end{array}$ & $\begin{array}{c}\text { Guillaume } \\
\text { de L'Isle's } \\
\text { Carte de } \\
\text { Tartarie } \\
\text { (1706) [22] }\end{array}$ & $\begin{array}{l}\text { d'Anville's } \\
\text { Carte la } \\
\text { plus } \\
\text { generale et } \\
\text { qui } \\
\text { comprend } \\
\text { la Chine, } \\
\text { la Tartarie } \\
\text { chinoise, et } \\
\text { le Thibet } \\
\text { (1737) } 6]\end{array}$ & Remarks \\
\hline $\begin{array}{l}\text { Ard } \\
\text { Basjirt al } \\
\text { Dāhbila }\end{array}$ & $\begin{array}{l}\text { Baschirdo- } \\
\text { rum Horda }\end{array}$ & Pascarti & $\begin{array}{l}\text { Baskirie ou } \\
\text { Pays des } \\
\text { Baskirzi }\end{array}$ & & Bashkortostan \\
\hline $\begin{array}{l}\text { Jebel } \\
\text { Qūfāyāa }\end{array}$ & & & M. de Caf & & Siberia \\
\hline Dādamī & & Dademi & Dademi & & $\begin{array}{l}\text { Perhaps mod. Dadem- } \\
\text { Ata, a shrine to the } \\
\text { south of the city of } \\
\text { Oral in western Ka- } \\
\text { zakhstan. On the } \\
\text { Idrisi map, a town } \\
\text { Hānqākat is placed } \\
\text { east of Dādamī. This } \\
\text { is evidently mod. } \\
\text { Anqaty, a town south } \\
\text { of Oral in Western } \\
\text { Kazakhstan. }\end{array}$ \\
\hline $\begin{array}{l}\text { Šahadrūj/ } \\
\text { Sahrūḥ }\end{array}$ & & Schadrug & Sahadrug & & Russia \\
\hline Siqrā & & Cafra? & Sacra & & \\
\hline Marșān & & Marzan & Marzan & & \\
\hline $\begin{array}{l}\text { Ġaūzbān/ } \\
\text { Ġaurān }\end{array}$ & & & Chauran & & $\begin{array}{l}\text { Perhaps mod. } \\
\text { Qusman, a town south } \\
\text { of Oral in Western } \\
\text { Kazakhstan. }\end{array}$ \\
\hline Ḩarqān & & Arkan & $\begin{array}{l}\text { Charcan ou } \\
\text { Arcan }\end{array}$ & & $\begin{array}{l}\text { Perhaps mod. Qara- } \\
\text { ghandy, a town south } \\
\text { of Oral in Western } \\
\text { Kazakhstan. }\end{array}$ \\
\hline
\end{tabular}




\begin{tabular}{|c|c|c|c|c|c|}
\hline Darqū & & & Darcu & & \\
\hline Daranda & & & Daranda & & \\
\hline Badeġa & & & Badega & & \\
\hline Ḩīām & & Hyan & Hyam & & $\begin{array}{l}\text { Perhaps, it refers to } \\
\text { the Jem River (Emba } \\
\text { in Russian) in Wes- } \\
\text { tern Kazakhstan. }\end{array}$ \\
\hline $\begin{array}{l}\text { Ġargiun } \\
\text { /Ġorgoz }\end{array}$ & & & Garghun & & $\begin{array}{l}\text { The Irgiz River in } \\
\text { Aktobe and Kostanay } \\
\text { regions in Kazakh- } \\
\text { stan. }\end{array}$ \\
\hline Jājān & & & Giagian & & \\
\hline nahr rūḍa & & Rudhan & $\begin{array}{l}\text { R. de } \\
\text { Rudhan }\end{array}$ & & \\
\hline Danbāha & & Daubana & Danhaba & & $\begin{array}{l}\text { Perhaps, Zhympyty or } \\
\text { Zhambayty, a town } \\
\text { south of Oral in West- } \\
\text { ern Kazakhstan. }\end{array}$ \\
\hline Loḩmān & & Lochman & Locman & & $\begin{array}{l}\text { Perhaps, Ulyqpan- } \\
\text { shegen ('shegen' } \\
\text { means well in Ka- } \\
\text { zakh), a place south } \\
\text { of Oral in Western } \\
\text { Kazakhstan. }\end{array}$ \\
\hline Ġarīān & & Cherman & German & & \\
\hline Dahlān & Teras & Taras & $\begin{array}{l}\text { Taras ou } \\
\text { Dahlan }\end{array}$ & Taraz & Kazakhstan \\
\hline $\begin{array}{l}\text { Salaḥ̄ } \\
\text { /Salḥ̄ì }\end{array}$ & Salg & & & Shalg & $\begin{array}{l}\text { Shiljī, Shelji or Shalji, } \\
\text { a city near Țarāz }[12, \\
\text { p. } 87 ; 34, \text { p. } 119 ; 30, \\
\text { p. } 445]\end{array}$ \\
\hline $\begin{array}{l}\text { Barsjan al } \\
\text { Sufla }\end{array}$ & & & & Bersagian & $\begin{array}{l}\text { Barskhān or Lower } \\
\text { Barskhān near Taraz. } \\
\text { According to ibn } \\
\text { Khurradādhbih, Low- } \\
\text { er Barskhān was situ- } \\
\text { ated three farsakhs } \\
\text { east of Țarāz (near } \\
\text { mod. Taraz). }\end{array}$ \\
\hline Bark & & & & Borac & $\begin{array}{l}\text { Mod. Merki in sou- } \\
\text { thern Kazakhstan }\end{array}$ \\
\hline $\begin{array}{l}\text { Buhaire } \\
\text { Tehāma }\end{array}$ & & $\begin{array}{l}\text { Lac } \\
\text { Theama }\end{array}$ & & & Kazakhstan \\
\hline Jarlak & & & & Haulac & \\
\hline Bakālak & & & & $\begin{array}{l}\text { M. } \\
\text { Shabalak }\end{array}$ & \\
\hline Ailaq & Eilach & & Ilac & Ilak & Uzbekistan \\
\hline Saikant & & & Tachkunt & Tashkunt & Tashkent \\
\hline Al Šāšs & & & Alchach & Al Shash & Uzbekistan \\
\hline Fārāb & & Farah & $\begin{array}{l}\text { Farab ou } \\
\text { Otrar }\end{array}$ & $\begin{array}{l}\text { Otrar ou } \\
\text { Farab }\end{array}$ & Kazakhstan \\
\hline
\end{tabular}




\begin{tabular}{|c|c|c|c|c|c|}
\hline $\begin{array}{l}\text { Šāaḡān } \\
\text { /Șabrān }\end{array}$ & & & Sabran & Sabran & $\begin{array}{l}\text { Mod. Sauran in Ka- } \\
\text { zakhstan. }\end{array}$ \\
\hline $\begin{array}{l}\text { Jebel } \\
\text { Mazḡār }\end{array}$ & & $\begin{array}{l}\text { Moreghar } \\
\text { M. }\end{array}$ & $\begin{array}{l}\text { M. } \\
\text { Moreghar }\end{array}$ & & $\begin{array}{l}\text { Mugodzhar Hills in } \\
\text { the Aktobe Region of } \\
\text { northwestern Kazakh- } \\
\text { stan. }\end{array}$ \\
\hline $\begin{array}{l}\text { Nahr } \\
\text { Morǵa }\end{array}$ & & Margha R. & Margha & & \\
\hline Nahr Jīhūn & & & Gihun R. & & Uzbekistan \\
\hline $\begin{array}{l}\text { Nahr al } \\
\text { Šās }\end{array}$ & & Iaxartes & $\begin{array}{l}\text { R. de } \\
\text { Sihun ou } \\
\text { d'Alchach }\end{array}$ & $\begin{array}{l}\text { Sihon ou } \\
\text { Sirr olim } \\
\text { Jaxartes }\end{array}$ & Tajikstan-Uzbekistan \\
\hline Ūasah & & & & Wasah & \\
\hline Asfinjab & & Isfenztab & & Eshsijab & $\begin{array}{l}\text { Old name for Sayram } \\
\text { in southern Kazakh- } \\
\text { stan. }\end{array}$ \\
\hline Al Sog̀d & & & & Al Sogd & Uzbekistan \\
\hline Damūrīa & & Damuria & & & $\begin{array}{l}\text { Tabar or Tuwur in the } \\
\text { Old Turkic inscription } \\
\text { and Chubu'er during } \\
\text { the Yuan period, mod. } \\
\text { Dawo'er near } \\
\text { Khorgos in Western } \\
\text { Xinjiang. }\end{array}$ \\
\hline Qaranīṭia & & $\begin{array}{l}\text { Lac } \\
\text { Carantia }\end{array}$ & & & Kazakhstan \\
\hline Dahrāh & & Darha & & & \\
\hline $\begin{array}{l}\text { Hāqāan } \\
\text { Hizizilj }\end{array}$ & & $\begin{array}{l}\text { Chagan } \\
\text { Calachitce }\end{array}$ & & $\begin{array}{l}\text { Kakan de } \\
\text { Kazalg' }\end{array}$ & Kazakhstan \\
\hline $\begin{array}{l}\text { Barsjan } \\
\text { al'alia }\end{array}$ & & & & $\begin{array}{l}\text { Bersagian } \\
\text { la Haute }\end{array}$ & $\begin{array}{l}\text { Upper Barskhān was } \\
\text { on the southern shore } \\
\text { of the Lake Issyk-Kul } \\
\text { (mod. Barskaun } \\
\text { hillfort on the River } \\
\text { Barskaun). }\end{array}$ \\
\hline Ațās & & & & Aatas & Kyrgyzstan \\
\hline $\begin{array}{l}\text { Jebel al } \\
\text { Batm/ } \\
\text { Botm }\end{array}$ & & & & $\begin{array}{l}\text { M.de } \\
\text { Botom }\end{array}$ & $\begin{array}{l}\text { Buttam Mountains, by } \\
\text { this name they under- } \\
\text { stood all the moun- } \\
\text { tainous region be- } \\
\text { tween the upper } \\
\text { courses of the Amu- } \\
\text { Darya and Syr-Darya, } \\
\text { distinguishing First, } \\
\text { Central, and Outer } \\
\text { Buttam (evidently the } \\
\text { Hisar, Zarafshh, and } \\
\text { Turkestan ranges) [ } 31 \text {, } \\
\text { p. 446; 8, p. 82] }\end{array}$ \\
\hline Ošrusana & Esreusina & & & $\begin{array}{l}\text { Oshrusa- } \\
\text { nah }\end{array}$ & Tajikstan \\
\hline Hojanda & & Cotzend & & Kogenda & Tajikstan \\
\hline
\end{tabular}




\begin{tabular}{|l|l|l|l|l|l|}
\hline Kās̄ān & & Casan & & & Uzbekistan \\
\hline Harmuq & & Horma & & & \\
\hline Țibet & Thebet & $\begin{array}{l}\text { Thibet ou } \\
\text { Tobrot et } \\
\text { Tobbat }\end{array}$ & & & \\
\hline Salūnīa & & Sachania & & & \\
\hline Banjara & & Bengiar & & & \\
\hline
\end{tabular}

\section{Map \\ The Itil (Volga) and Syr-Darya Basins' Cities on the Matteo Ricci's World}

Ricci’s (Li Madou 利瑪竇, 1552-1610) and Li Zhizao’s (李之藻, 1565-1630) map of "Kunyu wanguo quantu" (Complete Geographical Map of Ten Thousand Countries) was printed in 1602 [34]. The fourth edition, known as "Liangyi xuanlan tu" (兩儀玄覽圖Map of Observing the Mysteries of the Heaven and the Earth), was printed in 1603 [11, p. 26, plates 57, 58, 59; 35, p. 673-694; 54, p. 46, n. 43]

According to Zhang Qiong, Ricci's major Western sources in these areas were Alessandro Piccolomini (1508-1578), Abraham Ortelius (1527-1598), Gerardus Mercator (1512-1594), Petrus Plancius (1552-1622), and Christopher Clavius [54, p. 49, n. 46].

In my opinion, Ricci's World Map was effectively a translation of information from Ptolemy's "World map", Arabic maps such as Idrīs̄i, Marco Polo, Chinese, and European cartographers.

Theatrum Orbis Terrarum (Theater of the World) by Abraham Ortelius, first published in 1570 , was reissued in more than thirty editions over the next forty years. This map was based on a mixture of Jesuit, Arabic, and earlier sources, including the Tartaria map intitled "Tartariae Sive Magni Chami Regni typus" (hereafter Ortelius, Tartariae Sive Magni Chami Regni tÿpus 1570). Ortelius also included Anthony Jenkinson's rare map of Russia (called as Russiae, Moscoviae et Tartariae Descriptio) drawn in 1562 (hereafter Anthony Jenkinson/Ortelius 1562) [37]. Much of what we know about Anthony Jenkinson's (1529-1611) map is from Ortelius atlas. These became the basis of the historians beginning in the nineteenth century. Only in the 1987 did Jenkinson's unique wall map come to light, in Poland. This map entitled "Nova absolutaque Russiae, Moscoviae, et Tartariae, descriptio authore Antonio Jenkinsono Anglo, Clemente Adamo edita, et a Nicolao Reinoldo Londinensi, ari insculpta. Anno salutis, 1562". According to Krystyna Szykuła, the original turned out to be much larger than Ortelius' 44 by $35,3 \mathrm{~cm}$; it measures $101.7 \times 81.7 \mathrm{~cm}[45, \text { p. } 325-340]^{1}$.

South and east of the Caspian Sea, there are six figures of Khans. They are (going from the south): "Ismail Sophi" near the Ardabil town ("Ardwen" in the map); "Kvrcot Chan" near Balkh ("Balgh" in the map); to the north of "montes paraponise" - "Alie Chan" near Afsow (Aqsu) and Andugan ("Audeghen" in the map, Andeghen on the Anthony Jenkinson/Ortelius 1562; modern Andijan); "Mahvmet chan" in "Shamarchan" region; "Blag chan" in "Boghar" region (with

\footnotetext{
${ }^{1}$ I would like to thank Dr. Roman Hautala for his help in the reading of the original Latin
} text. 
cities "Cofin", "Ghudowa"=Ghijduvan); "Azim chan" in "Turkmen" region; and "Aphis chan" in "Taskent" region, to the north of "TaJkent" city.

"Ismail Sophi" near the Ardabil town ("Ardwen" in the map) is the Latin corruption of Ismail Sefewi (1487-1525), the founder of the Safavid Dynasty. Jenkinson called him Ismael Sophie [15, p. 132, 152]. In 1562, Jenkinson visited the court of the great Sophie, called Shaw Tamasso (Shah Tahmasp, 1514-1576) $[15$, p. 343].

"Kvrcot Chan" near Balkh ("Balgh" in the map), to the north of "montes paraponise". According to a passage on the map, related to this Khan (Princeps hic cum Indis plurima habet certamina, qui ad austrum illi finitimi sunt), "this prince is at war with the Indians, who are his neighbors from the south" [26, legend 23]. Perhaps, Kurkani or Gurkani is a self-designated name for the Timurid khans, after Temur's title Gurkan, the Persianized form of the Mongolian kürägän, "son-inlaw", a title he assumed after his marriage to a Chinggisid princess. This Gurkan should be Babur (1483-1530).

"Alie Chan" north of Kashgaria (Cafcara in the map), near Audeghen or Acfow (=Aqsu, the capital city of Moghulistan). There is a picture of khan here, with the following legend: "Cafcarae princeps Mahumetanus est, ac cum Kirgijs bella mouet" [26, legend 24a]. Perhaps, this is a corruption of Ālācha khan, the nickname of Sultan Akhmad Khan (died 1503), a khan of Moghulistan [18, p. 121]. He was the second son of Yunus Khan (1416-1487).

"Aphis chan" in "Taskent" region, to the north of "Tafkent" city. Here is a legend: "Rex hic aduersus Cassachios assidua bella mouet, quae gens nuper prope exterminata fuerat" ("This King is waging a continual war against Khasack tribes. Once they have been close to extermination" [46, p. 129]). Perhaps, it refers to Darwish Khan (1557-1578), the ruler of Tashkent, a son of Nawruz Akhmed Khan (1510-1556).

"Mahvmet chan" in "Shamarchan" region is, perhaps, Pir Muhammed Khan (1511-1561), the Khan of Samarqand.

"Blag chan" in "Boghar" region is Abdullah Khan II (1534-1598), the ruler of the Khanate of Bukhara. He was a King of Bukhara at the time of Jenkinson's visit in 1558 [3, p. 206, 247].

"Azim chan" in "Turkmen" region, with the legend: "Turcomannorum imperium inter quinque fratres est partitum, quorum qui primas tenet Azim Chan nominatus est. Reliqui uero, Soltani appellantur. Quisque solum oppida uel potius castra sub ditione et imperio suo tenent. Horum Vrgence Principem locum tenet. Incolae Mahumeticam sectam agnoscunt, uiuuntque iuxta Nagaiorum consuetudinem, ac cum Persarum Principem (uulgo Sophi nuncupato) continenter belli gerantur". (The Turkoman Empire is divided between five brothers. One of them, the leading one, is called Azim Khan. The rest are called Sultans. Each of them holds the cities, or rather castles, at his own power and command. Among them [castles], Urgench takes the first place. The inhabitants recognize the Mohammedan sect, live according to Nogai customs, and constantly wage war with the ruler of the Persians [called Sophi among the common people]).

Azim chan is Hājim Khān, also known as Hạjj Muḥammad Khān (1519-1603), the tenth Uzbek ruler from the Shibanid dynasty in the Khwarezm state, who ruled from 1558 to 1603, the grandfather of Abū al-Ghāzī Bahādur Khān (1605-1664) $[3$, p. $272 ; 4$, vol. I, p. $270 ; 15$, p. 68, 70]. According to Jenkinson, all the land from 
the Caspian Sea to this city of Urgench, is called the land of Turkeman, and is a subject to Azim Khan [15, p. 72; 5, p. 307].

North and northeast of the Caspian Sea ("Mare Caspivm" in the map), two Hordas of Nagaia (Noghay) occur, centered in Saraichik (Jerachick) and Shakashick (JhakaJhick), and a Horda of Cassackia (Qazaq Khanate), with legend. There is a quite detailed fragment of territory of Cassakia (=Qazaq Khanate), which is therefore why it should be quote here $[15$, p. cxxxii, 90; 49, p. 71; 5, p. $185 ; 42$, p. 396]. The name of this region is marked as Cassakia. In a passage on the map, Anthony Jenkinson even discussed the custom of the Kirgessi (=Cassaks): "Kirgessi gens cateruatim degit, id est in hordis, habetque ritum huiufmodi; cum re diuinam ipforum Jacerdos peragit, Janguinem, lac et fimu iumentorum accipit, ac terre mifcet, inque vas quoddam infundit, eóque arborem $\int$ candit, atque cõcione habita, in populum $\int$ pargit, atque hęc a $\int$ per $\int i o$ pro Deo habetur et colitur. Cum quis

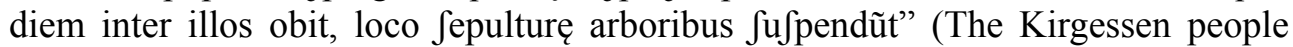
live in troops or hordes. They have the following custom: when a priest performs a religious ceremony, he obtains blood, milk and dung of beasts of burden, and mixes it with earth. He pours this in a specific vessel and climbs a tree with it, and when there is a gathering, he sprinkles it over the people, and this sprinkling is considered to be divine, and is worshipped. When someone of them dies, that person is hung up in a tree by way of burial). This edition is almost identical with the Anthony Jenkinson's unique wall map of Russia (1562), but with minor differences in characters: "Kirge $\int s i$ gens eft, quae cateruatim degit, id est in Hordis, aßidueque cum mhogholis gerit, habetque ritum iftiufmodi. Ipsorum antiftes aut Jacrificus, quo tempore rem diuinam peragit, Janguine, lacte et fimo iumentorum acceptis, ac terrae mixtis, ac in uas quoddam infusis, una cum hoc arborem $\int$ candit, atque hinc diu ad populum concionatus, in $\int$ tultam plebeculam $\int$ pergit. Populus uero in terram pronus, adorabundufque, aspersiunculam hanc pro deo colit: firmeque credit, nihil e $\iint e$ perinde falutare ac terram, pecus, armentaque et cum quis inter eos diem obit, loco fepulturae arboribus $\int \mathrm{u} \int$ pendit" (The Kirgiz are a people living in detachments, that is, in the Hordes. This people is also incessantly waging wars with the Mongols [=Moghols - N.K.], and this people have the following ritual: When a high priest or sacrificer performs a service, he takes the blood, milk, and dung of the beasts of burden, mixes them with earth and pours them into one vessel. Then he climbs a tree with it and turns from there to the people who have long gathered below for this. He sprinkles the foolish common people from the tree. The people, bowing to the ground and praying, honor these splashes for God. They also strongly believe that there is nothing more to be worshiped than land and flocks and herds. And when one of them dies, instead of burying him, they hang him from the trees) [46, p. 140].

According to Anthony Jenkinson, "the people that warre (=war) against Taskent are called Cassaks of the law of Mahomet, and they which warre (=war) with the said country of Caskayre (=Kashkaria) are called Kings (=Kirghis), Gentiles and Idolaters" [15, p. 90-91; 5, p. 185].

According to Peter Heylyn, "Kirgessi not burying their dead bodies, as in other places, but hanging them upon Trees, though they think again: certain enough that they will be devoured or sweetened, before they return back to the same station. Much reverence yet they give their Priests, by whom sanctified and besprinkled in their public meeting, with a certain mixture, compounded of Blood, Milk, Earth, 
and Cow-dung, a most sweet Confection, but good enough for them that desire no better. And yet with these the Muscovite is fain to hold fair compliance, and to send them every year some Presents for fear they should join with the Nagaians: or otherwise disturb him in his Caspian Trade down the Volga River" [39, lib III, p. 167].

In this part of the map of "Kunyu wanguo quantu", Ricci called Cassakia as Ge'ermo 哥兒墨 (=Ge'erheishi哥兒黑士, =Kirgessi on the Jenkinson's map), with a passage: "Ciguo sizhe bumai, dan yi tielian gua qishi gan (=yu) shulin 此國死者不埋, 但以鐵鏈挂其尸干 $(=$ 于)樹林” (The dead bodies in this country are not buried, but they hang their bodies in the woods with iron chains).

Moving beyond this sphere, immediately neighboring countries such as Astrakhan, Turchestan, and Zagatai are labeled using the names of Turkic origin. In this part of the map of "Kunyu wanguo quantu", to begin from the north, the following cities or countries are marked: Nanwoya 南斡牙(=Nagaia on the Jenkinson's map); Yasidalagan 亚私大蠟甘(=Astracan on the Jenkinson's map) [2, p. 272]; Wu'erwa he ji Yide 勿尔瓦河即亦得 (=Volga et Hedel in Ortelius, Tartariae Sive Magni Chami Regni tÿpus 1570); Tu'erkesitang 土兒克私堂 (=Turchestan), Chawatai 察瓦泰 (=Zagatai). These names do not describe places or countries but, rather, ethnicities. The two place-names in the Caspian appearing as Yimu guo 一目國and Nüren guo女人國, were known by Chinese geographers. However, these are simply translation of Arimaspi, Amazones.

For other locations on the map in the Itil (Volga) and Syr-Darya Basins, see Table II.

Table II:

The Itil (Volga) and Syr-Darya Basins' cities on the Matteo Ricci’s World Map

\begin{tabular}{|c|l|l|l|}
\hline № & \multicolumn{1}{|c|}{$\begin{array}{c}\text { Kunyu wanguo } \\
\text { quantu }\end{array}$} & \multicolumn{1}{|c|}{ European sources/maps } & Modern location \\
\hline 1. & $\begin{array}{l}\text { Beigao hai 北高海 } \\
\text { (literally, “High Sea } \\
\text { of the North”) }\end{array}$ & $\begin{array}{l}\text { Mar de Bachu (Ortelius, Tartariae Sive } \\
\text { Magni Chami Regni tÿpus 1570) }\end{array}$ & Caspian Sea \\
\hline 2. & $\begin{array}{l}\text { Ge'ermoqi } \\
\text { 葛尔莫奇 }\end{array}$ & Colmack (Anthony Jenkinson 1562) & Qalmaq \\
\hline 3. & Ge’ermo 哥兒墨 & $\begin{array}{l}\text { Most likely an error for Ge'erheishi } \\
\text { 哥兒黑士, it refers to Kirgessi, another } \\
\text { name for Kazakhs (Jenkinson/Ortelius } \\
\text { 1562); also see 39, lib. III, 165, 167. }\end{array}$ & Qazaq \\
\hline 4. & $\begin{array}{l}\text { Qi'ermuxi guo } \\
\text { 其尔目西國 }\end{array}$ & $\begin{array}{l}\text { Ciremißorum horda (Ortelius, Tartariae } \\
\text { Sive Magni Chami Regni tÿpus 1570) }\end{array}$ & Russia \\
\hline 5. & Qilijili 乞里吉里 & $\begin{array}{l}\text { Khirkhīz or Qirqiz, a Turkish tribe of the } \\
\text { ancient country of Southern Siberia whose } \\
\text { name is also written as Khirkhīz, Khārkhīr } \\
\text { or Kirghiz (EI2, “Kirgiz"). The name ap- } \\
\text { pears as either Qirqir or Qirqiz or Qirqīz in } \\
\text { Arabic accounts. }\end{array}$ & $\begin{array}{l}\text { Mod. Khakasia, } \\
\text { Russia }\end{array}$ \\
\hline 6. & Yu'aliya 育阿利亞 & $\begin{array}{l}\text { Vgori (Ugria), on Jenkinson’s map } \\
\text { "lorghoria”, the country of “Zlata Baba”, or } \\
\text { Golden Old Woman, worshipped by the } \\
\text { people of Obdora at the mouth of the Obi } \\
\text { (Jenkinson/Ortelius 1562). }\end{array}$ & Russia \\
\hline
\end{tabular}




\begin{tabular}{|c|c|c|c|}
\hline 7. & Xiajia 黠戛 & $\begin{array}{l}\text { Xiajiasi點戛斯(Xin Tangshu 217b. 6146). } \\
\text { Another name for Khirkhiz or Qirqiz. See } \\
\text { Qilijili. }\end{array}$ & Khakasia \\
\hline 8. & Tianfang 天方 & $\begin{array}{l}\text { The place name or country name Tianfang } \\
\text { in Chinese was almost used to refer to } \\
\text { Mecca. According to the Mingshi, } \\
\text { Tianfang, ancient Yunchong (al-Hijāz), was } \\
\text { known as Tiantang (Heaven or Heavenly } \\
\text { Realm), and also Mojia (Mecca) (Mingshi } \\
\text { 332.8621: } \\
\text { 天方, 古笏沖地, 一名天堂, 又曰默伽). } \\
\text { According to its location on the map (east } \\
\text { of Turkestan, west of Dada), this was prob- } \\
\text { ably a mistake made by the copyist, and it } \\
\text { should refer to Tanguth, Tangunt or Tangut. } \\
\text { The Tanguts, called the Dangxiang (党項) } \\
\text { or Western Xia (Xixia 西夏) in Chinese, } \\
\text { was an empire which existed from 1038 to } \\
1227 \text { in modern northwestern China and } \\
\text { southernmost Mongolia. }\end{array}$ & \\
\hline 9. & $\begin{array}{l}\text { Yasidalagan } \\
\text { 亚私大蠟甘 }\end{array}$ & $\begin{array}{l}\text { Astracan (Jenkinson/Ortelius 1562; } \\
\text { Ortelius, Tartariae Sive Magni Chami } \\
\text { Regni tÿpus } 1570 ; 40)\end{array}$ & Astrakhan \\
\hline 10. & $\begin{array}{l}\text { Wu'erwa he ji Yide } \\
\text { 勿尔瓦河即亦得 }\end{array}$ & $\begin{array}{l}\text { Literally means "Volga is Itil," =Volga et } \\
\text { Hedel (Jenkinson/Ortelius } 1562 \text {; Ortelius, } \\
\text { Tartariae Sive Magni Chami Regni tÿpus } \\
\text { 1570); according to Peter Heylyn, "Rha, by } \\
\text { the modern Latines called Volgo; by the } \\
\text { Tartars, Edi", see } 39 \text {, lib. III, } 165 \text {. }\end{array}$ & Volga River \\
\hline 11. & Dumona 杜没那 & $\begin{array}{l}\text { Tumen (Jenkinson/Ortelius 1562; Plancius } \\
\text { 1594) }\end{array}$ & Russia \\
\hline 12. & $\begin{array}{l}\text { Bai'ermiya } \\
\text { 白尔米雅 }\end{array}$ & $\begin{array}{l}\text { Permia/Weliki Perm (Jenkinson/Ortelius } \\
\text { 1562; 40; 32) }\end{array}$ & $\begin{array}{l}\text { Perm Krai, } \\
\text { Russia }\end{array}$ \\
\hline 13. & Heduola 合多蠟 & $\begin{array}{l}\text { Obdora (Jenkinson/Ortelius 1562; Ortelius, } \\
\text { Tartariae Sive Magni Chami Regni tÿpus } \\
\text { 1570) }\end{array}$ & $\begin{array}{l}\text { Obdor (Обдор, } \\
\text { Обдория) }\end{array}$ \\
\hline 14. & Moyi 莫奕 & Moyeda (Jenkinson/Ortelius 1562) & Russia \\
\hline 15. & Gongduola 公多蠟 & $\begin{array}{l}\text { Condora (Jenkinson/Ortelius 1562; } \\
\text { Ortelius, Tartariae Sive Magni Chami } \\
\text { Regni tÿpus 1570) }\end{array}$ & Kondia or Konda \\
\hline 16. & Duyina 杜亦拏 & Dvina (Jenkinson/Ortelius 1562) & Russia \\
\hline 17. & Nanwoya 南斡亚 & Nagaia (Jenkinson/Ortelius 1562; 40) & $\begin{array}{l}\text { modern Veliky } \\
\text { Ustyug, Russia }\end{array}$ \\
\hline 18. & Wuduye 兀督耶 & Vstiuge (Jenkinson/Ortelius 1562) & Russia \\
\hline 19. & $\begin{array}{l}\text { Mai'erduya } \\
\text { 麥兒杜雅 }\end{array}$ & Mordva (Jenkinson/Ortelius 1562; 40) & Russia \\
\hline 20. & $\begin{array}{l}\text { Shidiya Yimao nei } \\
\text { 是的亞意貌内 }\end{array}$ & $\begin{array}{l}\text { Scithia intra Imaum Montem/Schithia intra } \\
\text { Imaum (the Scythia within the Imaus) } \\
\text { (Totius Europae et Asiae Tabula } \\
\text { Geographica, Auctore Thoma D. } \\
\text { Aucupario. Edita Argentorati, }\end{array}$ & $\begin{array}{l}\text { Scythia was di- } \\
\text { vided by Mount } \\
\text { Imaus into two } \\
\text { parts, called re- } \\
\text { spectively Scyth- }\end{array}$ \\
\hline
\end{tabular}




\begin{tabular}{|c|c|c|c|}
\hline & & mdxxii/1522), also see $[39$, p. 161,168$]$. & $\begin{array}{l}\text { ia intra Imaum, i. } \\
\text { e. on the north- } \\
\text { western side of } \\
\text { the range, and } \\
\text { Scythia extra } \\
\text { Imaum, on its } \\
\text { southeastern side. }\end{array}$ \\
\hline 21. & $\begin{array}{l}\text { Shideya Yimao wai } \\
\text { 是的亞意貌外 }\end{array}$ & $\begin{array}{l}\text { Scithia extra Imaum Montem/Schithia ultra } \\
\text { Imaum (The Scythia beyond the Imaus) } \\
\text { (Totius Europae et Asiae Tabula } \\
\text { Geographica, Auctore Thoma D. } \\
\text { Aucupario. Edita Argentorati, mdxxii/1522) }\end{array}$ & \\
\hline 22. & $\begin{array}{l}\text { Jitayixige } \\
\text { 忌塔意西葛 }\end{array}$ & $\begin{array}{l}\text { Kitaifko (Asia ex magna orbis terrae } \\
\text { descriptione Gerardi Mercatoris desumpta, } \\
\text { studio et industria G.M. Iunioris. Edita } \mathrm{A}^{\circ} \\
\text { M.D.LXXXVII/1587). }\end{array}$ & \\
\hline 23. & Yimao shan 意貌山 & $\begin{array}{l}\text { Imaus Mons (Asia ex magna orbis terrae } \\
\text { descriptione Gerardi Mercatoris desumpta, } \\
\text { studio et industria G.M. Iunioris. Edita } A^{\mathrm{o}} \\
\text { M.D.LXXXVII/1587) }\end{array}$ & \\
\hline 24. & Heiqitai 黑其泰 & Kara Kithai $(40)$ & \\
\hline 25. & Chawatai 察瓦泰 & Zagatai (Ortelius 1570) & \\
\hline 26. & $\begin{array}{l}\text { Maolinayi’er } \\
\text { 貌力那亦尔 }\end{array}$ & $\begin{array}{l}\text { Mavrenaher (Ortelius, Tartariae Sive Magni } \\
\text { Chami Regni tÿpus 1570) }\end{array}$ & Transoxiana \\
\hline 27. & $\begin{array}{l}\text { Maolinanke'er } \\
\text { 貌力南客尔 }\end{array}$ & $\begin{array}{l}\text { Mavrenaher (Ortelius, Tartariae Sive Magni } \\
\text { Chami Regni tÿpus 1570) }\end{array}$ & Transoxiana \\
\hline 28. & $\begin{array}{l}\text { Tu'erkesitang } \\
\text { 土兒克私堂 }\end{array}$ & Turchestan (40) & Kazakhstan \\
\hline 29. & Baiying 白營 & $\begin{array}{l}\text { Poin, Peim (Ortelius, Tartariae Sive Magni } \\
\text { Chami Regni tÿpus 1570); Pein visited by } \\
\text { Marco Polo, ancent town to the east of } \\
\text { Khotan }\end{array}$ & $\begin{array}{l}\text { Modern Keriya, } \\
\text { Xinjiang }\end{array}$ \\
\hline 30. & Yao’ergeng 藥尔耕 & $\begin{array}{l}\text { Ergimvl/Ergimul (Ortelius, Tartariae Sive } \\
\text { Magni Chami Regni tÿpus 1570) }\end{array}$ & $\begin{array}{l}\text { Evirghol? (Mod- } \\
\text { ern Araturk? } \\
\text { Chinese Yiwu } \\
\text { 伊吾) }\end{array}$ \\
\hline 31. & Hami 哈密 & $\begin{array}{l}\text { Camul (Ortelius, Tartariae Sive Magni } \\
\text { Chami Regni tÿpus 1570) }\end{array}$ & Qumul \\
\hline 32. & Tulufan 土魯番 & $\begin{array}{l}\text { Turfan (Ortelius, Tartariae Sive Magni } \\
\text { Chami Regni tÿpus 1570) }\end{array}$ & Turfan, Xinjiang \\
\hline 33. & Yanqi 焉耆 & $\begin{array}{l}\text { Calis (Ortelius, Tartariae Sive Magni } \\
\text { Chami Regni tÿpus 1570) }\end{array}$ & $\begin{array}{l}\text { Qarashahar, } \\
\text { Xinjiang }\end{array}$ \\
\hline 34. & $\begin{array}{l}\text { Dasigengdi } \\
\text { 大廝耕諦 }\end{array}$ & $\begin{array}{l}\text { Taskent (Ortelius, Tartariae Sive Magni } \\
\text { Chami Regni tÿpus 1570) }\end{array}$ & $\begin{array}{l}\text { Tashkent, } \\
\text { Uzbekistan }\end{array}$ \\
\hline 35. & Suye he 素葉河 & $\begin{array}{l}\text { By "Suiye he" most likely refers to the Sur } \\
\text { or Syr river in Central Asia, anc. Jaxartes. } \\
\text { In Ortelius, Tartariae Sive Magni Chami } \\
\text { Regni tÿpus } 1570 \text {, it bears its Kazakh } \\
\text { name, Sirusion (=Syr Özen). }\end{array}$ & Syr-Darya \\
\hline 36. & $\begin{array}{l}\text { Sama’erhan } \\
\text { 撒馬兒罕 }\end{array}$ & $\begin{array}{l}\text { Samarchand (Ortelius, Tartariae Sive } \\
\text { Magni Chami Regni tÿpus 1570) }\end{array}$ & $\begin{array}{l}\text { Samarqand, } \\
\text { Uzbekistan }\end{array}$ \\
\hline
\end{tabular}




\begin{tabular}{|c|c|c|c|}
\hline 37. & $\begin{array}{l}\text { Da Congling } \\
\text { 大葱嶺 }\end{array}$ & $\begin{array}{l}\text { Monte Dalanguer (Ortelius, Tartariae Sive } \\
\text { Magni Chami Regni tÿpus 1570) }\end{array}$ & \\
\hline 38. & $\begin{array}{l}\text { Xuandu shan } \\
\text { 懸度山 }\end{array}$ & $\begin{array}{l}\text { Monte Vshonte (Ortelius, Tartariae Sive } \\
\text { Magni Chami Regni tÿpus 1570) }\end{array}$ & \\
\hline 39. & $\begin{array}{l}\text { Gaogasuo shan } \\
\text { 高葛娑山 }\end{array}$ & $\begin{array}{l}\text { Imaus mons qui \& Caucashus (Ortelius, } \\
\text { Tartariae Sive Magni Chami Regni tÿpus } \\
\text { 1570) }\end{array}$ & $\begin{array}{l}\text { Caucasus } \\
\text { Mountains }\end{array}$ \\
\hline 40. & $\begin{array}{l}\text { Dagelisidan } \\
\text { 大革里思旦 }\end{array}$ & $\begin{array}{l}\text { Tacalistan (Ortelius, Tartariae Sive Magni } \\
\text { Chami Regni tÿpus 1570) }\end{array}$ & Tokharistan? \\
\hline 41. & Dibula 地布蠟 & $\begin{array}{l}\text { Tipvra (Ortelius, Tartariae Sive Magni } \\
\text { Chami Regni tÿpus 1570) }\end{array}$ & Tripura, India? \\
\hline 42. & Sanguo 三國 & $\begin{array}{l}\text { Sim? (Ortelius, Tartariae Sive Magni } \\
\text { Chami Regni tÿpus 1570) }\end{array}$ & \\
\hline 43. & Yesaiba 耶塞拔 & $\begin{array}{l}\text { Iesel Bas (Ortelius, Tartariae Sive Magni } \\
\text { Chami Regni tÿpus 1570) }\end{array}$ & $\begin{array}{l}\text { Qyzyl Bash } \\
\text { (Read Head), } \\
\text { Turkic name for } \\
\text { Safavids }\end{array}$ \\
\hline 44. & Hejiaru 何加入 & $\begin{array}{l}\text { Ocrage (Ortelius, Persici Sive Sophorvm } \\
\text { Regni Typus } 1570 \text { ) }\end{array}$ & \\
\hline 45. & $\begin{array}{l}\text { Delili Dabolisitan } \\
\text { 得力利大伯里私旦 }\end{array}$ & $\begin{array}{l}\text { Diar Taperistan (Ortelius, Persici Sive } \\
\text { Sophorvm Regni Typus 1570) }\end{array}$ & \\
\hline 46. & Rulan 入蘭 & $\begin{array}{l}\text { Gilan (Ortelius, Persici Sive Sophorvm } \\
\text { Regni Typus 1570) }\end{array}$ & Iran \\
\hline 47. & $\begin{array}{l}\text { Ladasi 蠟大私 } \\
\end{array}$ & $\begin{array}{l}\text { Tares (Ortelius, Persici Sive Sophorvm } \\
\text { Regni Typus 1570) }\end{array}$ & \\
\hline 48. & Senouli 色耨利 & $\begin{array}{l}\text { Seriar (Ortelius, Persici Sive Sophorvm } \\
\text { Regni Typus 1570) }\end{array}$ & \\
\hline 49. & $\begin{array}{l}\text { Tabasidan } \\
\text { 陀拔斯单 } \\
\end{array}$ & $\begin{array}{l}\text { Taperistan (Ortelius, Persici Sive Sophorvm } \\
\text { Regni Typus 1570) }\end{array}$ & Iran \\
\hline 50. & Jiasi 加私 & $\begin{array}{l}\text { Kax or Kath (Cante in the Jenkinson's map) } \\
\text { (Ortelius, Tartariae Sive Magni Chami } \\
\text { Regni tÿpus 1570) }\end{array}$ & $\begin{array}{l}\text { Beruniy, } \\
\text { Karakalpakstan }\end{array}$ \\
\hline 51. & Rexisitu 惹西廝突 & $\begin{array}{l}\text { Sirisitvr (Ortelius, Persici Sive Sophorvm } \\
\text { Regni Typus 1570) }\end{array}$ & \\
\hline 52. & $\begin{array}{l}\text { Yixidiru } \\
\text { 伊西帝宜入 }\end{array}$ & $\begin{array}{l}\text { Istigias (Ortelius, Tartariae Sive Magni } \\
\text { Chami Regni tÿpus 1570) }\end{array}$ & \\
\hline 53. & $\begin{array}{l}\text { Gelazuoni } \\
\text { 哥蠟作泥 }\end{array}$ & $\begin{array}{l}\text { Charassan (Ortelius, Persici Sive Sophorvm } \\
\text { Regni Typus 1570) }\end{array}$ & Khorasan \\
\hline 54. & Yimu guo 一目國 & $\begin{array}{l}\text { Arimaspi (Sarmatia et Scythia Russia et } \\
\text { Tartaria Europaea, 1697) }\end{array}$ & $\begin{array}{l}\text { A legendary tribe } \\
\text { of one-eyed peo- } \\
\text { ple of northern } \\
\text { Scythia who lived } \\
\text { in the foothills of } \\
\text { the Riphean } \\
\text { Mountains, vari- } \\
\text { ously identified } \\
\text { with the Ural } \\
\text { Mountains or the } \\
\text { Carpathians }\end{array}$ \\
\hline 55. & Nvren guo 女人國 & $\begin{array}{l}\text { Amazones (Sarmatia et Scythia Russia et } \\
\text { Tartaria Europaea, 1697) }\end{array}$ & \\
\hline
\end{tabular}




\begin{tabular}{|c|c|c|c|}
\hline 56. & $\begin{array}{l}\text { Bodiwu'erqi } \\
\text { 伯帝兀尔祁 }\end{array}$ & Petigorski (Jenkinson/Ortelius 1562) & $\begin{array}{l}\text { Beshtau (Горы } \\
\text { Пятигорья), } \\
\text { Northern Cauca- } \\
\text { sus }\end{array}$ \\
\hline 57. & $\begin{array}{l}\text { Mohede hu } \\
\text { 墨何的湖 }\end{array}$ & Palus Meotis (Jenkinson/Ortelius 1562) & Sea of Azov \\
\hline 58. & Qilimoya 契利末牙 & Crimea (Jenkinson/Ortelius 1562) & Crimea \\
\hline 59. & Gaidaqi 蓋大期 & $\begin{array}{l}\text { Caitachi (Ortelius, Tvrcici Imperii } \\
\text { Descriptio 1570) }\end{array}$ & Crimea \\
\hline 60. & $\begin{array}{l}\text { Wachaliya } \\
\text { 瓦茶里亞 }\end{array}$ & $\begin{array}{l}\text { Gazaria (Ortelius, Tvrcici Imperii } \\
\text { Descriptio 1570) }\end{array}$ & \\
\hline 61. & $\begin{array}{l}\text { Genaduole } \\
\text { 葛捺多勒 }\end{array}$ & $\begin{array}{l}\text { Anadole (Ortelius, Tvrcici Imperii } \\
\text { Descriptio 1570) }\end{array}$ & Turkey \\
\hline 62. & Bocu 波促 & $\begin{array}{l}\text { Bozoc (Ortelius, Tvrcici Imperii Descriptio } \\
\text { 1570) }\end{array}$ & Turkey \\
\hline 63. & Borang 撥讓 & $\begin{array}{l}\text { Pegian (Ortelius, Tvrcici Imperii Descriptio } \\
1570 \text { ) }\end{array}$ & Turkey \\
\hline 64. & Runou 入毞 & $\begin{array}{l}\text { Genic (Ortelius, Tvrcici Imperii Descriptio } \\
\text { 1570) }\end{array}$ & \\
\hline 65. & $\begin{array}{l}\text { Yamaxiya } \\
\text { 亞馬西亞 }\end{array}$ & $\begin{array}{l}\text { Amasia (Ortelius, Tvrcici Imperii } \\
\text { Descriptio 1570) }\end{array}$ & Turkey \\
\hline 66. & Boliliuni 波里六泥 & $\begin{array}{l}\text { Bolli Roni (Ortelius, Tvrcici Imperii } \\
\text { Descriptio 1570) }\end{array}$ & \\
\hline 67. & Suwasi 蘇襪斯 & $\begin{array}{l}\text { Svvas (Ortelius, Tvrcici Imperii Descriptio } \\
1570 \text { ) }\end{array}$ & Sivas, Turkey \\
\hline 68. & $\begin{array}{l}\text { Fuluodeme’er } \\
\text { 縛羅得抹尔 }\end{array}$ & Volodemer (Jenkinson/Ortelius 1562) & $\begin{array}{l}\text { Vladimir } \\
\text { (Владимир-на- } \\
\text { Клязьме) } \\
\end{array}$ \\
\hline 69. & $\begin{array}{l}\text { Ouluoba } \\
\text { Sha'ermaqiya } \\
\text { 歐邏巴沙尔馬齊亞 }\end{array}$ & $\begin{array}{l}\text { Sarmatia Europaea (Ptolemy’s "World } \\
\text { map"; Sarmatia et Scythia Russia et } \\
\text { Tartaria Europaea, 1697). Detailed } \\
\text { description of Sarmatia Europaea, see 39, } \\
\text { lib. III, 167. }\end{array}$ & \\
\hline 70. & $\begin{array}{l}\text { Yaxiya } \\
\text { Sha'ermaqiya } \\
\text { 亞細亞沙尔馬齊亞 }\end{array}$ & $\begin{array}{l}\text { Sarmatia Asiatica (Ortelius, Tartariae Sive } \\
\text { Magni Chami Regni tÿpus 1570) }\end{array}$ & \\
\hline 71. & $\begin{array}{l}\text { Esugedaye } \\
\text { 額索各荅耶 }\end{array}$ & $\begin{array}{l}\text { Scythia (see Peter Heylyn 1677, lib. III } \\
\text { 161, 168; Sarmatia et Scythia Russia et } \\
\text { Tartaria Europaea, 1697) }\end{array}$ & \\
\hline 72. & $\begin{array}{l}\text { Mengrililiya } \\
\text { 孟日力里亞 }\end{array}$ & Mengrelia & $\begin{array}{l}\text { A historic prov- } \\
\text { ince in the west- } \\
\text { ern part of Geor- } \\
\text { gia. }\end{array}$ \\
\hline 73. & $\begin{array}{l}\text { Re'a'erruyana } \\
\text { 熱阿尔入亞那 }\end{array}$ & $\begin{array}{l}\text { Georgiani (Ortelius, Tartariae Sive Magni } \\
\text { Chami Regni tÿpus 1570) }\end{array}$ & Georgia \\
\hline 74. & Danai he 大乃河 & Tanais (Jenkinson/Ortelius 1562) & Russia \\
\hline 75. & $\begin{array}{l}\text { Chilagaiya } \\
\text { 赤蠟蓋亞 }\end{array}$ & $\begin{array}{l}\text { Erachaian (Ortelius, Persici Sive Sophorvm } \\
\text { Regni Typus 1570) }\end{array}$ & \\
\hline 76. & Dalaba 打喇巴 & $\begin{array}{l}\text { Starabat (Ortelius, Persici Sive Sophorvm } \\
\text { Regni Typus 1570) }\end{array}$ & Iran \\
\hline
\end{tabular}




\begin{tabular}{|c|c|c|c|}
\hline 77. & Moshantu 没善土 & $\begin{array}{l}\text { Mesandaran (Ortelius, Persici Sive } \\
\text { Sophorvm Regni Typus 1570) }\end{array}$ & Iran \\
\hline 78. & $\begin{array}{l}\text { Hulumosi } \\
\text { 忽魯謨斯 }\end{array}$ & $\begin{array}{l}\text { Ormuz (Ortelius, Persici Sive Sophorvm } \\
\text { Regni Typus 1570); (also see 39, lib. III } \\
\text { 147) }\end{array}$ & Iran \\
\hline 79. & Xi'erman 溪尔曼 & $\begin{array}{l}\text { Chirman (Ortelius, Persici Sive Sophorvm } \\
\text { Regni Typus 1570) }\end{array}$ & Kerman, Iran \\
\hline 80 . & Bosi 波斯 & $\begin{array}{l}\text { Farsi (Ortelius, Persici Sive Sophorvm } \\
\text { Regni Typus 1570) }\end{array}$ & Iran \\
\hline 81. & $\begin{array}{l}\text { Yadeborang } \\
\text { 亞的伯讓 }\end{array}$ & $\begin{array}{l}\text { Adilbegian (Ortelius, Persici Sive } \\
\text { Sophorvm Regni Typus 1570) }\end{array}$ & \\
\hline 82. & $\begin{array}{l}\text { Ge'erdalan } \\
\text { 葛尔打蘭 }\end{array}$ & $\begin{array}{l}\text { Caldaran (Ortelius, Persici Sive Sophorvm } \\
\text { Regni Typus 1570) }\end{array}$ & \\
\hline 83. & $\begin{array}{l}\text { Dige’erbo } \\
\text { 帝葛兒伯 }\end{array}$ & $\begin{array}{l}\text { Diarbech (Ortelius, Persici Sive Sophorvm } \\
\text { Regni Typus 1570) }\end{array}$ & \\
\hline 84. & Shawusi 沙勿私 & $\begin{array}{l}\text { Savas (Ortelius, Persici Sive Sophorvm } \\
\text { Regni Typus 1570) }\end{array}$ & \\
\hline 85. & Wade'er 瓦得尔 & $\begin{array}{l}\text { Gavadel (Ortelius, Persici Sive Sophorvm } \\
\text { Regni Typus 1570) }\end{array}$ & Pakistan \\
\hline 86. & Gebu'er 葛步尔 & $\begin{array}{l}\text { Cabvl (Ortelius, Persici Sive Sophorvm } \\
\text { Regni Typus 1570) }\end{array}$ & $\begin{array}{l}\text { Kabul, } \\
\text { Afghanistan }\end{array}$ \\
\hline 87. & Gandaga 甘打噶 & $\begin{array}{l}\text { Candahar (Ortelius, Persici Sive Sophorvm } \\
\text { Regni Typus 1570) }\end{array}$ & Afghanistan \\
\hline 88. & $\begin{array}{l}\text { Yindusitang } \\
\text { 印度燍當 }\end{array}$ & $\begin{array}{l}\text { Indostan (Ortelius, Indiae Orientalis } \\
\text { Insvlarvmqve Adiacientivm typus } 1570 \text { ) }\end{array}$ & India \\
\hline 89. & Yalagan 亞蠟敢 & $\begin{array}{l}\text { Aracam (Ortelius, Indiae Orientalis } \\
\text { Insvlarvmqve Adiacientivm typus 1570) }\end{array}$ & \\
\hline 90. & Mengdao 孟道 & $\begin{array}{l}\text { Mandao (Ortelius, Indiae Orientalis } \\
\text { Insvlarvmqve Adiacientivm typus 1570) }\end{array}$ & \\
\hline 91. & Banggela 榜葛剌 & $\begin{array}{l}\text { Bengala Ortelius, Indiae Orientalis } \\
\text { Insvlarvmqve Adiacientivm typus } 1570 \text { ) }\end{array}$ & Bangladesh \\
\hline 92. & Piniu 琵牛 & $\begin{array}{l}\text { Pegu (Ortelius, Indiae Orientalis } \\
\text { Insvlarvmqve Adiacientivm typus 1570) }\end{array}$ & \\
\hline 93. & $\begin{array}{l}\text { Ma’erdamang } \\
\text { 馬兒大莽 }\end{array}$ & $\begin{array}{l}\text { Martabam (Ortelius, Indiae Orientalis } \\
\text { Insvlarvmqve Adiacientivm typus 1570) }\end{array}$ & \\
\hline 94. & $\begin{array}{l}\text { Jia'erdandan } \\
\text { 加尔旦旦 }\end{array}$ & $\begin{array}{l}\text { Cardandan (Ortelius, Indiae Orientalis } \\
\text { Insvlarvmqve Adiacientivm typus 1570) }\end{array}$ & \\
\hline
\end{tabular}

\section{The Itil (Volga) Basin, Siberia, and Kazakh Steppe's Place Names in the Qing Dynasty (1644-1912) Maps}

After the Qing-Zhunghar war, the Qing sought to expand its empire into Tibet and Zhungharia. The Qing dynasty took advantage of international changes in Central Asia. The geographical ambitions of the Qing dynasty in Central Asia led to the redrawing of the frontier boundaries between Russia and the Qing as well as to the crushing of the vassal state of Zhunghar Khanate in 1760 by Qing armies. The Qing dynasty produced important new maps of unprecedented scale and accuracy as political and ideological weapons in their struggle for control of Central Asia. The first was the Jesuit atlas of China: the famous "Kangxi Atlas" (Kangxi Huangyu quanlan tu 康熙皇舆全览圖 [Map with a Complete View of Imperial Territory]), drawn on 
the basis of surveys conducted by European Jesuits using mathematical techniques and presented to the emperor in 1718. German scholar Walter Fuchs have made significant contributions in the study of the Kangxi Atlas, but the territory of the Atlas did not include the Central Asia and Kazakh Steppe [20]. The most widely known version of the map was that done by Jean-Baptiste d'Anville, printed by JeanBaptiste du Halde in his Description de la Chine, published in Paris in 1735. In 1737, he published the full atlas of the Qing in The Hague. This map of d'Anville was the basis of the Asian map to the Russian and English geographical research of the nineteenth century. After his initial victory over Dawachi in 1755, the Qianlong emperor (r. 1736-1795) ordered the compilation of large-scale maps. It was finished in 1772 and are now known variously as the Qianlong neifu yutu 乾隆内府舆圖 (Terrestrial Map of the Imperial Repository of Qianlong Reign), Qianlong huangyu quantu 乾隆皇舆全圖 (Complete Atlas of the Empire from the Qianlong Reign), Yudi quantu 輿地全圖 (The Whole atlas of the Empire), Qianlong shisan pai tu 乾隆十三排圖 (Map of the Qianlong Reign in Thirteen Rows). The Qianlong neifu yutu appeared in many different editions and different formats. The title of the version of the Qianlong atlas in the 1966 reprint is Qingdai yitong ditu 清代一統地圖 (China's National Atlas of Ching Dynasty) [55; 52].

German scholar M.J. Klaproth translated the place names of Central Asia (Asie centrale on the BnF online digital library of Gallica, the website of the French National Library in Paris) in the Qianlong neifu yutu into French [27]. For the sake of comparison, here is a list of place names of the Central Asia, Volga Basin, and adjacent areas in the Qianlong neifu yutu and the Asie centrale as follows (note: Manchu place name object type: bira (bila) = river; hoton (hetun) = city; alin = mountain; omo $($ emo $)=$ the sea; gashan $($ keshan $)=$ country; sekiyen $($ siqin $)=$ water source, source; dabakhan = pass or hill; in addition, the lacks place names from Asie centrale are marked with *; modern Cyrillic and Latin place names are filled in the "Remarks" column):

Table III:

The place names of Central Asia and the Itil Basin in Qianlong neifu yutu

\begin{tabular}{|c|c|c|c|c|}
\hline № & Qianlong neifu yutu [52] & $\begin{array}{c}\text { location } \\
\text { on } \\
\text { Qian- } \\
\text { long } \\
\text { neifu } \\
\text { yutu }\end{array}$ & Asie centrale & Remarks \\
\hline \multicolumn{5}{|c|}{ Fifth rows west 3 [五排西三] } \\
\hline 1. & E'erqisi bila 額爾齊斯必拉 & $\begin{array}{c}\text { west } \\
34-35\end{array}$ & $\begin{array}{l}\text { F. Ertsiss } \\
\text { F. Irtish }\end{array}$ & Ertis River \\
\hline 2. & Duomu hala 多穆哈拉 & $\begin{array}{l}\text { west } \\
35-36\end{array}$ & Tom-khara & $\begin{array}{c}\text { on the border of Russia- } \\
\text { Kazakhstan }\end{array}$ \\
\hline 3. & Tailan Ha'erhai 台蘭哈爾海 & $\begin{array}{c}\text { west } \\
33-34\end{array}$ & $\begin{array}{l}\text { Tairam } \\
\text { khalkhai }\end{array}$ & \\
\hline 4. & Mosige bila 謨斯格必拉 & $\begin{array}{l}\text { west } \\
36-37\end{array}$ & F. Mossghe & \\
\hline
\end{tabular}




\begin{tabular}{|c|c|c|c|c|}
\hline 5. & $\begin{array}{l}\text { Yiximusigui hetun } \\
\text { 伊錫穆斯歸和屯 }\end{array}$ & $\begin{array}{c}\text { west } \\
37-38\end{array}$ & $\begin{array}{c}\text { Ville } \\
\text { Ischimskoi }\end{array}$ & Ишимский/Ishimsky \\
\hline 6. & Yisikemu bila 伊斯克穆必拉 & $\begin{array}{c}\text { west } \\
38-39\end{array}$ & F. Ischim & Ишим/Ishim River \\
\hline 7. & Bu'erhasutaibila 布爾哈蘇台必拉 & $\begin{array}{c}\text { west } \\
38-39\end{array}$ & $\begin{array}{c}\text { F. } \\
\text { Bourkhassoutai }\end{array}$ & \\
\hline 8. & Duola bila多拉必拉 & $\begin{array}{c}\text { west } \\
37-38\end{array}$ & Tara* & Tapa/Tara River \\
\hline 9. & Duola hetun 多拉和屯 & $\begin{array}{c}\text { west } \\
39-40\end{array}$ & Tara* & Tapa/Tara city \\
\hline 10. & Bayan ha'er hana 巴彥哈爾哈納 & $\begin{array}{c}\text { west } \\
39-40\end{array}$ & $\begin{array}{l}\text { Bayan-khara- } \\
\text { khana }\end{array}$ & \\
\hline 11. & Yi'erdisi bila 伊爾底斯必拉 & $\begin{array}{c}\text { west } \\
40-41\end{array}$ & Ertsiss* & Epтic/Ertis \\
\hline 12. & $\begin{array}{l}\text { Dimuyansigui hetun } \\
\text { 底穆彥斯歸和屯 }\end{array}$ & $\begin{array}{l}\text { west } \\
39-40\end{array}$ & & Demianovsky \\
\hline 13. & Waga gashan 瓦噶噶珊 & $\begin{array}{l}\text { west } \\
40-41\end{array}$ & Vagay gashan* & Вагай/Vagay \\
\hline 14. & Balake hetun 巴拉克和屯 & $\begin{array}{c}\text { west } \\
41-42\end{array}$ & Abalak* & $\begin{array}{l}\text { Абалак/Abalak [41, } \\
\text { T. VI, p. 393] }\end{array}$ \\
\hline 15. & Tuobo'er hetun 托博爾和屯 & $\begin{array}{c}\text { west } \\
42-43\end{array}$ & Tobol* & Тобольск/Tobolsk \\
\hline 16. & Exi’er bila 額錫爾必拉 & $\begin{array}{c}\text { west } \\
44-45\end{array}$ & Esil* & Есіл/Esil \\
\hline 17. & Tuobo'er bila 托博爾必拉 & $\begin{array}{c}\text { west } \\
44-45\end{array}$ & Tobol* & Тобыл/ Tobol \\
\hline 18. & Yizete bila 伊澤特必拉 & $\begin{array}{l}\text { west } \\
46-47\end{array}$ & Iset* & Исеть/Iset \\
\hline 19. & Dumen hetun 都捫和屯 & $\begin{array}{l}\text { west } \\
46-47\end{array}$ & Tumen* & $\begin{array}{l}\text { Тюмень/Tyumen [41, } \\
\text { T. VI, p. 404] }\end{array}$ \\
\hline 20. & Dula bila 都拉必拉 & $\begin{array}{l}\text { west } \\
45-46\end{array}$ & Tura* & Typa/Tura \\
\hline 21. & $\begin{array}{c}\text { Da'erlinsigui } \\
\text { hetun達爾林斯歸和屯 }\end{array}$ & $\begin{array}{c}\text { west } \\
44-45\end{array}$ & $\begin{array}{l}\text { Darlingskoi } \\
\text { (ville) }\end{array}$ & \\
\hline 22. & $\begin{array}{c}\text { Wudiduo'ersiga } \\
\text { hetun烏底多爾斯噶和屯 }\end{array}$ & $\begin{array}{c}\text { west } \\
45-46\end{array}$ & $\begin{array}{l}\text { Oudidorsga } \\
\text { (ville) }\end{array}$ & \\
\hline 23. & $\begin{array}{l}\text { Naiweyangsigui hetun } \\
\text { 面衛陽斯歸和屯 }\end{array}$ & $\begin{array}{c}\text { west } \\
48-49\end{array}$ & $\begin{array}{l}\text { Nayuiyangskoi } \\
\text { (ville) }\end{array}$ & \\
\hline 24. & Naiwa bila 鼏瓦必拉 & $\begin{array}{c}\text { west } \\
48-49\end{array}$ & F. Naiwa & Нейва/Neiva/Nevya \\
\hline 25. & Wutega hetun烏特噶和屯 & $\begin{array}{c}\text { west } \\
48-49\end{array}$ & Outega (ville) & $\begin{array}{c}\text { Утяк/ Utyakovo } \\
{[13, \text { p. 490] }}\end{array}$ \\
\hline 26. & Jugu'er hetun 巨古爾和屯 & $\begin{array}{c}\text { west } \\
52-53\end{array}$ & & \\
\hline
\end{tabular}




\begin{tabular}{|c|c|c|c|c|}
\hline \multicolumn{5}{|c|}{ Fifth rows west 4 [五排西四] } \\
\hline 27. & Samara bila 薩瑪拉必拉 & $\begin{array}{c}\text { west } \\
53-54\end{array}$ & F. Samara & Самара/Samara River \\
\hline 28. & Samala hetun 薩瑪拉和屯 & $\begin{array}{c}\text { west } \\
53-54\end{array}$ & Samara (ville) & Самара/Samara city \\
\hline 29. & Dedu'er gashan 德都爾噶珊 & $\begin{array}{c}\text { west } \\
54-55\end{array}$ & Dedour (ville) & \\
\hline 30. & Badaya gashan 巴達雅噶珊 & $\begin{array}{c}\text { west } \\
55-56\end{array}$ & & \\
\hline 31. & Mosikewa 墨斯克瓦 & $\begin{array}{c}\text { west } \\
54-55\end{array}$ & Kheskewa & Моркваши? \\
\hline 32. & Wusa keshan 烏薩克珊 & $\begin{array}{c}\text { west } \\
54-55\end{array}$ & Oussa (village) & \\
\hline 33. & Gama bila 噶瑪必拉 & $\begin{array}{l}\text { west } \\
54-55\end{array}$ & & $\begin{array}{c}\text { Кама/Kama. } \\
\text { Also called as Cholman } \\
\text { Idel [41, T. VI, p. } 167]\end{array}$ \\
\hline 34. & Wo'erga bila 倭爾噶必拉 & $\begin{array}{c}\text { west } \\
54-55\end{array}$ & F. Wolga & Волга/Volga \\
\hline 35. & Xishuan bila 錫栓必拉 & $\begin{array}{l}\text { west } \\
54-55\end{array}$ & Sitsiuen & Сызран/Syzran River? \\
\hline 36. & Gazan hetun 噶贊和屯 & $\begin{array}{l}\text { west } \\
59-60\end{array}$ & Kazan (ville) & Казан/Kazan \\
\hline 37. & Sula bila 苏拉必拉 & $\begin{array}{l}\text { west } \\
60-61\end{array}$ & & $\begin{array}{c}\text { Сура/Sura } \\
\text { or } \\
\text { Сульча/Sulcha }\end{array}$ \\
\hline 38. & Ega bila 鄂噶必拉 & $\begin{array}{l}\text { west } \\
61-62\end{array}$ & & \\
\hline 39. & Gelesima bila 格勒斯瑪必拉 & $\begin{array}{c}\text { west } \\
63-64\end{array}$ & & \\
\hline 40. & Basiduofu hetun 巴斯多傅和屯 & $\begin{array}{l}\text { west } \\
64-65\end{array}$ & & \\
\hline 41. & Mikehai hetun 密科亥和屯 & $\begin{array}{l}\text { west } \\
64-65\end{array}$ & & \\
\hline 42. & Delatema hetun 德拉特瑪和屯 & $\begin{array}{l}\text { west } \\
65-66\end{array}$ & & \\
\hline 43. & Sateguo hetun 薩特郭和屯 & $\begin{array}{c}\text { west } \\
65-66\end{array}$ & & \\
\hline 44. & $\begin{array}{l}\text { Sefei'a'siga gashan } \\
\text { 色非阿斯噶噶珊 }\end{array}$ & $\begin{array}{l}\text { west } \\
59-60\end{array}$ & $\begin{array}{l}\text { Sefiasga } \\
\text { (village) }\end{array}$ & $\begin{array}{l}\text { Свияжскъ/Sviyazhsk } \\
{[41, \text { T. VI, p. } 180 ; 13,} \\
\text { p. } 489]\end{array}$ \\
\hline 45. & Dula bila 都拉必拉 & $\begin{array}{c}\text { west } \\
60-61\end{array}$ & & \\
\hline 46. & Dedusi hetun 德都斯和屯 & $\begin{array}{c}\text { west } \\
57-58\end{array}$ & Dedous (ville) & $\begin{array}{l}\text { Tetus, Тетюши } \\
\text { /Tetyushi }\end{array}$ \\
\hline
\end{tabular}




\begin{tabular}{|c|c|c|c|c|}
\hline 47. & Suzhawaya bila 苏扎瓦雅必拉 & $\begin{array}{c}\text { west } \\
51-52\end{array}$ & F. Soutchawaya & \\
\hline 48. & Guoleisi hetun 郭雷斯和屯 & $\begin{array}{c}\text { west } \\
57-58\end{array}$ & & \\
\hline 49. & Laisuo'er hetun 來索爾和屯 & $\begin{array}{c}\text { west } \\
57-58\end{array}$ & & Лаишево (тат. Лаеш)? \\
\hline 50. & Nisina hetun 尼斯納和屯 & $\begin{array}{c}\text { west } \\
60-61\end{array}$ & & $\begin{array}{l}\text { Нижний (Новгород) } \\
\text { /Nizhny (Novgorod) }\end{array}$ \\
\hline 51. & $\begin{array}{l}\text { Guoluoguowaiside hetun } \\
\text { 郭羅郭歪斯德和屯 }\end{array}$ & $\begin{array}{c}\text { west } \\
61-62\end{array}$ & & $\begin{array}{l}\text { Гороховец/ } \\
\text { Gorokhovets }\end{array}$ \\
\hline 52. & $\begin{array}{l}\text { Woluodimo’er hetun } \\
\text { 倭羅底謨爾和屯 }\end{array}$ & $\begin{array}{c}\text { west } \\
62-63\end{array}$ & & $\begin{array}{c}\text { Володимғрь/Vladimir } \\
\text { (Владимир-на- } \\
\text { Клязьме) }\end{array}$ \\
\hline 53. & Gelisima bila 格勒斯瑪必拉 & & & Клязьма/Klzayma \\
\hline 54. & Mosikua hetun 謨斯誇和屯 & & & Москва/Moscow \\
\hline 55. & Luosan hetun 羅散和屯 & & & Рязань/Ryazan \\
\hline 56. & Danbofu hetun 丹博傅和屯 & & & Тамбов/Tambov \\
\hline \multicolumn{5}{|c|}{ Sixth rows west 3 六排西三 } \\
\hline 57. & E’erqisi bila 额尔齐斯必拉 & $\begin{array}{c}\text { west } \\
32-33\end{array}$ & F. Ertiss & Ертіс/Ertis \\
\hline 58. & Dabusun nao'er 达布孙淖尔 & $\begin{array}{c}\text { west } \\
31-32\end{array}$ & Lac de Sel & \\
\hline 59. & Nanuyi bila 纳努衣必拉 & $\begin{array}{c}\text { west } \\
30-31\end{array}$ & F. Nay & \\
\hline 60. & Nanuyi seqin 纳努衣色钦 & $\begin{array}{c}\text { west } \\
29-30\end{array}$ & Source du Nay & \\
\hline 61. & Talong Ha'erhai 塔隆哈尔海 & $\begin{array}{l}\text { west } \\
30-31\end{array}$ & $\begin{array}{l}\text { Taroung- } \\
\text { kharkhai }\end{array}$ & \\
\hline 62. & Bogui Ha'erhai 博归哈尔海 & $\begin{array}{c}\text { west } \\
31-32\end{array}$ & $\begin{array}{l}\text { Bogoui- } \\
\text { kharkhai }\end{array}$ & \\
\hline 63. & $\begin{array}{l}\text { Ha'erda'erjin Ha'erhai } \\
\text { 哈尔达尔金哈尔海 }\end{array}$ & $\begin{array}{c}\text { west } \\
31-32\end{array}$ & $\begin{array}{l}\text { Aldarghin- } \\
\text { kharkhai }\end{array}$ & \\
\hline 64. & Chahan E'erbo 察汉鄂尔博 & $\begin{array}{c}\text { west } \\
31-32\end{array}$ & Tsachan-Olbo & Ақ Оба (Ақ Үбі) \\
\hline 65. & Kala E’erbo 喀拉鄂尔博 & $\begin{array}{c}\text { west } \\
31-32\end{array}$ & Khara-Olbo & $\begin{array}{c}\text { Қара Оба (Қара } \\
\text { Үбi)/Qara Oba }\end{array}$ \\
\hline 66. & Eluosi Xi'er bila 鄂罗斯锡尔必拉 & $\begin{array}{c}\text { west } \\
32-33\end{array}$ & Oross-Sirbi & \\
\hline 67. & Hailatu 海拉图 & $\begin{array}{c}\text { west } \\
31-32\end{array}$ & Khairatou & \\
\hline 68. & Hai'er kumen bila 海尔库扪必拉 & $\begin{array}{c}\text { west } \\
31-32\end{array}$ & $\begin{array}{l}\text { F. Khair } \\
\text { koumun }\end{array}$ & \\
\hline
\end{tabular}




\begin{tabular}{|c|c|c|c|c|}
\hline 69. & Tulun gaiqi nao'er 图伦该奇淖尔 & $\begin{array}{c}\text { west } \\
31-32\end{array}$ & $\begin{array}{l}\text { Lac Touloun } \\
\text { gaighi }\end{array}$ & \\
\hline 70. & Ba'erqiketu 巴尔奇克图 & $\begin{array}{c}\text { west } \\
32-33\end{array}$ & Bartsiktou & \\
\hline 71. & Handahaitu 汉达海图 & $\begin{array}{c}\text { west } \\
31-32\end{array}$ & Khandakhaitou & \\
\hline 72. & Tuibo'er 推博尔 & $\begin{array}{c}\text { west } \\
32-33\end{array}$ & Tchouibor & \\
\hline 73. & Heyue'er kalonggu 和岳尔喀隆古 & $\begin{array}{c}\text { west } \\
32-33\end{array}$ & $\begin{array}{l}\text { Khoyor } \\
\text { Karoungou }\end{array}$ & \\
\hline 74. & A'erqituhan alin 阿尔齐图汉阿林 & $\begin{array}{c}\text { west } \\
32-33\end{array}$ & $\begin{array}{c}\text { M. } \\
\text { Artsitoukhan }\end{array}$ & \\
\hline 75. & Eluosi Buli'er 鄂罗斯布里尔 & $\begin{array}{c}\text { west } \\
32-33\end{array}$ & Oross Boulir & \\
\hline 76. & $\begin{array}{l}\text { Eluosi Cenboluote } \\
\text { 鄂罗斯参博罗特 }\end{array}$ & $\begin{array}{c}\text { west } \\
32-33\end{array}$ & $\begin{array}{l}\text { Sempolot (ville } \\
\text { Russe) }\end{array}$ & $\begin{array}{l}\text { Семей/Semey [41, } \\
\text { T. VII, p. 22] }\end{array}$ \\
\hline 77. & $\begin{array}{l}\text { Eluosi Jiange'er tula } \\
\text { 鄂罗斯鑑格尔图拉 }\end{array}$ & $\begin{array}{c}\text { west } \\
32-33\end{array}$ & $\begin{array}{c}\text { Gher-Toura } \\
\text { (=Kenggher- } \\
\text { Toura) } \\
\text { Ville Russe } \\
\text { Oustkamen- } \\
\text { gorsk }\end{array}$ & $\begin{array}{c}\text { Өскемен (Усть- } \\
\text { Каменогорск)/ } \\
\text { Öskemen }\end{array}$ \\
\hline 78. & Wuliyasutu 乌里雅苏图 & $\begin{array}{c}\text { west } \\
32-33\end{array}$ & & Улиясуту/Uliyasutu \\
\hline 79. & Cha'er bila 察尔必拉 & $\begin{array}{c}\text { west } \\
32-33\end{array}$ & F. Tsar & Шаp/Shar \\
\hline 80. & Kundulun Cha'er 坤都仑察尔 & $\begin{array}{c}\text { west } \\
33-34\end{array}$ & $\begin{array}{l}\text { Koundouloun } \\
\text { Tsar }\end{array}$ & \\
\hline 81. & Wulan Chuqian 乌兰楚迁 & $\begin{array}{c}\text { west } \\
32-33\end{array}$ & $\begin{array}{l}\text { Oulian- } \\
\text { Tchoutsian }\end{array}$ & \\
\hline 82. & Wuxun Chuqian 乌逊楚迁 & $\begin{array}{c}\text { west } \\
32-33\end{array}$ & $\begin{array}{l}\text { Oussou- } \\
\text { Tchoutsian }\end{array}$ & \\
\hline 83. & Tu'ergun 图尔根 & $\begin{array}{c}\text { west } \\
32-33\end{array}$ & Tourghen & \\
\hline 84. & Wulan Bulake 乌兰布拉克 & $\begin{array}{c}\text { west } \\
32-33\end{array}$ & Oulan boulak & \\
\hline 85. & Abu 阿布 & $\begin{array}{c}\text { west } \\
32-33\end{array}$ & Abou & \\
\hline 86. & Ebugen 鄂布根 & $\begin{array}{c}\text { west } \\
32-33\end{array}$ & & \\
\hline 87. & Eluosi E’erboke 鄂罗斯鄂尔博克 & $\begin{array}{c}\text { west } \\
32-33\end{array}$ & Oross Obbok & \\
\hline 88. & Eluosi Hami’er 鄂罗斯哈蜜尔 & $\begin{array}{c}\text { west } \\
32-33\end{array}$ & $\begin{array}{c}\text { Oross } \\
\text { Kaningdsoung }\end{array}$ & \\
\hline
\end{tabular}




\begin{tabular}{|c|c|c|c|c|}
\hline 89. & Ke'ertuositai 科尔托斯台 & $\begin{array}{c}\text { west } \\
32-33\end{array}$ & Kortosotai & \\
\hline 90. & Abulaikeyi 阿布赖克衣 & $\begin{array}{c}\text { west } \\
33-34\end{array}$ & Ablai-keï & $\begin{array}{c}\text { Абылайкит/Ablaykit } \\
\text { (Ablayin Qiyid) }\end{array}$ \\
\hline 91. & A'ertai Mulu 阿尔台穆鲁 & $\begin{array}{c}\text { west } \\
30-31\end{array}$ & $\begin{array}{l}\text { Altay Mourou } \\
\text { (dos ou crête } \\
\text { de l'Altai) }\end{array}$ & \\
\hline 92. & Hai'er kumen bila 海尔库扪必拉 & $\begin{array}{c}\text { west } \\
31-32\end{array}$ & $\begin{array}{l}\text { F. Khair } \\
\text { koumun }\end{array}$ & \\
\hline 93. & Buketulamu bila 布克图拉穆必拉 & $\begin{array}{c}\text { west } \\
31-32\end{array}$ & F. Bouktourma & Бұқтырма/Bukhtarma \\
\hline 94. & Bulu'er bila 布鲁尔必拉 & $\begin{array}{c}\text { west } \\
31-32\end{array}$ & F. Bouroul & $\begin{array}{c}\text { Ақ Берел (Бергіел)/ } \\
\text { Aqberel }\end{array}$ \\
\hline 95. & Chui bila 吹必拉 & $\begin{array}{c}\text { west } \\
31-32\end{array}$ & F. Tchoui & \\
\hline 96. & Bu'ergake bila 布尔噶克必拉 & $\begin{array}{c}\text { west } \\
31-32\end{array}$ & F. Bourgak & \\
\hline 97. & Changjisitai bila 昌吉斯台必拉 & $\begin{array}{c}\text { west } \\
31-32\end{array}$ & F. Tchanghistai & $\begin{array}{l}\text { Шыңғыстай/ } \\
\text { Shyngghystay }\end{array}$ \\
\hline 98. & Changjisitai kalun 昌吉斯台喀伦 & $\begin{array}{c}\text { west } \\
31-32\end{array}$ & $\begin{array}{l}\text { Tchanghistai } \\
\text { Karaoul }\end{array}$ & \\
\hline 99. & Nalin bila 纳林必拉 & $\begin{array}{c}\text { west } \\
31-32\end{array}$ & & Нарын/Naryn \\
\hline 100. & A'ershatai bila 阿尔沙台必拉 & $\begin{array}{c}\text { west } \\
30-31\end{array}$ & F. Archatai & \\
\hline 101. & Eyiman bila 鄂衣满必拉 & $\begin{array}{c}\text { west } \\
30-31\end{array}$ & F. Oiman & \\
\hline 102. & Kukewusu 库克乌苏 & $\begin{array}{c}\text { west } \\
30-31\end{array}$ & $\begin{array}{c}\text { F. } \\
\text { Koukèoussou }\end{array}$ & \\
\hline 103. & $\begin{array}{l}\text { Hetuo'er dabahan } \\
\text { 和托和尔达巴汉 }\end{array}$ & $\begin{array}{l}\text { west } \\
29-30\end{array}$ & $\begin{array}{l}\text { M. Khotokhor } \\
\text { Dabakhan }\end{array}$ & \\
\hline 104. & Zha'erman bila 扎尔满必拉 & $\begin{array}{c}\text { west } \\
30-31\end{array}$ & F. Dcharman & Жарма/Zharma \\
\hline 105. & Kuba dabahan 库布达巴汉 & $\begin{array}{c}\text { west } \\
29-30\end{array}$ & $\begin{array}{l}\text { M. Koubou } \\
\text { Dabakhan }\end{array}$ & \\
\hline 106. & $\begin{array}{l}\text { Haji'er kumen bila } \\
\text { 哈集尔库扪必拉 }\end{array}$ & $\begin{array}{l}\text { west } \\
29-30\end{array}$ & $\begin{array}{l}\text { F. Khadsir } \\
\text { Koumun }\end{array}$ & \\
\hline 107. & A'erhute bila 阿尔胡特必拉 & $\begin{array}{c}\text { west } \\
29-30\end{array}$ & F. Arkhout & \\
\hline 108. & Chahan wusu 察汉乌苏 & $\begin{array}{l}\text { west } \\
29-30\end{array}$ & $\begin{array}{l}\text { F. Tsagan- } \\
\text { oussou }\end{array}$ & \\
\hline 109. & Chui bila 吹必拉 & $\begin{array}{c}\text { west } \\
29-30\end{array}$ & F. Tchoui & \\
\hline
\end{tabular}




\begin{tabular}{|c|c|c|c|c|}
\hline 110. & $\begin{array}{l}\text { Boluo Bu'ergasu bila } \\
\text { 博罗布尔噶苏必拉 }\end{array}$ & $\begin{array}{c}\text { west } \\
28-29\end{array}$ & $\begin{array}{c}\text { F. Boro- } \\
\text { bourgassoutai }\end{array}$ & \\
\hline 111. & Da'erqintu bila 达尔钦图必拉 & $\begin{array}{c}\text { west } \\
28-29\end{array}$ & F. Darkintou & \\
\hline 112. & Zhasitai bila 扎斯台必拉 & $\begin{array}{c}\text { west } \\
29-30\end{array}$ & F. Dchastai & \\
\hline 113. & Na'erga bila 纳尔噶必拉 & $\begin{array}{c}\text { west } \\
29-30\end{array}$ & F. Narga & \\
\hline 114. & Wukeke bila 乌克克必拉 & $\begin{array}{c}\text { west } \\
30-31\end{array}$ & F. Oukek & Укок/Ukek \\
\hline 115. & A'erchatu bila 阿尔察图必拉 & $\begin{array}{c}\text { west } \\
30-31\end{array}$ & F. Archatai & \\
\hline 116. & Hala bila 哈拉必拉 & $\begin{array}{c}\text { west } \\
30-31\end{array}$ & F. Khara & \\
\hline 117. & $\begin{array}{l}\text { Hezhuo'erbu'ergasutai } \\
\text { 和卓尔布尔噶苏台 }\end{array}$ & $\begin{array}{c}\text { west } \\
32-33\end{array}$ & $\begin{array}{c}\text { Khodcherbourk } \\
\text { hasoutai }\end{array}$ & \\
\hline 118. & Kundatu 坤达图 & $\begin{array}{c}\text { west } \\
32-33\end{array}$ & Koundatou & \\
\hline 119. & Wuliyasutu 乌里雅苏图 & $\begin{array}{c}\text { west } \\
32-33\end{array}$ & Oulanyasoutai & \\
\hline 120. & Wulanqihusutu 乌兰齐胡苏图 & $\begin{array}{c}\text { west } \\
32-33\end{array}$ & $\begin{array}{c}\text { Oulikhousouto } \\
\mathrm{u}\end{array}$ & \\
\hline 121. & Jinjilike bila 金集里克必拉 & $\begin{array}{c}\text { west } \\
37-38\end{array}$ & F. Ghindsilik & \\
\hline 122. & Bacha bila 巴差必拉 & $\begin{array}{c}\text { west } \\
37-38\end{array}$ & F. Batchai & \\
\hline 123. & Mohe'ercha'er 莫和尔察尔 & $\begin{array}{c}\text { west } \\
34-35\end{array}$ & F. Mokhor-tsar & \\
\hline 124. & Cha'er seqin 察尔色钦 & $\begin{array}{c}\text { west } \\
34-35\end{array}$ & Source de Tsar & \\
\hline 125. & Alake alin 阿拉克阿林 & $\begin{array}{c}\text { west } \\
34-35\end{array}$ & M. Alak & \\
\hline 126. & $\begin{array}{l}\text { Ta'ergusi Wuliyatai } \\
\text { 塔尔古斯乌里雅台 }\end{array}$ & $\begin{array}{c}\text { west } \\
33-34\end{array}$ & $\begin{array}{l}\text { F. Targous } \\
\text { Ouliatai }\end{array}$ & \\
\hline 127. & Ahaitu 阿海图 & $\begin{array}{c}\text { west } \\
33-34\end{array}$ & Akhaitou & \\
\hline 128. & Ebeitu 额贝图 & $\begin{array}{c}\text { west } \\
33-34\end{array}$ & Ebeitou & \\
\hline 129. & Wudatu 乌达图 & $\begin{array}{c}\text { west } \\
33-34\end{array}$ & Outatu & \\
\hline 130. & Tulutai 图鲁台 & $\begin{array}{c}\text { west } \\
33-34\end{array}$ & Touloutai & \\
\hline 131. & Kalaguo’er 喀拉郭尔 & $\begin{array}{c}\text { west } \\
33-34\end{array}$ & R. Kara-koul & \\
\hline
\end{tabular}




\begin{tabular}{|c|c|c|c|c|}
\hline 132. & Kukuguo'er 库库郭尔 & $\begin{array}{c}\text { west } \\
33-34\end{array}$ & $\begin{array}{l}\text { R. Koukou- } \\
\text { koul }\end{array}$ & \\
\hline 133. & E’erqisi bila 鄂尔齐斯必拉 & $\begin{array}{c}\text { west } \\
32-33\end{array}$ & F. Ertsis & \\
\hline 134. & $\begin{array}{l}\text { Kulan-aji'ergan bila } \\
\text { 库兰阿集尔干必拉 }\end{array}$ & $\begin{array}{c}\text { west } \\
32-33\end{array}$ & $\begin{array}{l}\text { F. Koulan- } \\
\text { adsirkhan }\end{array}$ & \\
\hline 135. & Lebuxi bila 勒布锡必拉 & $\begin{array}{c}\text { west } \\
37-38\end{array}$ & F. Lebssi & \\
\hline 136. & Chahan wusu 察罕乌苏 & $\begin{array}{c}\text { west } \\
37-38\end{array}$ & & Ақсу/Aqsu \\
\hline 137. & Kukuwusu 库库乌苏 & $\begin{array}{c}\text { west } \\
37-38\end{array}$ & $\begin{array}{l}\text { F. Koukou- } \\
\text { oussou }\end{array}$ & Көксу/Koksu \\
\hline 138. & Halata'er bila 哈拉塔尔必拉 & $\begin{array}{c}\text { west } \\
38-39\end{array}$ & F. Kharatal & Қаратал/Karatal \\
\hline 139. & Biji bila 毕集必拉 & $\begin{array}{c}\text { west } \\
38-39\end{array}$ & F. Bidsi & Быжы/Byzhy \\
\hline 140. & Cha'er bila 察尔必拉 & $\begin{array}{c}\text { west } \\
39-40\end{array}$ & & \\
\hline 141. & Xila nao'er 锡拉淖尔 & $\begin{array}{c}\text { west } \\
39-40\end{array}$ & L. Sira-noor & \\
\hline 142. & A'erhui alin 阿尔辉阿林 & $\begin{array}{c}\text { west } \\
40-41\end{array}$ & M. Arkhouy & \\
\hline 143. & Kukesali bila 库克萨里必拉 & $\begin{array}{c}\text { west } \\
40-41\end{array}$ & F. Kouksari & \\
\hline 144. & Bahanasi bila 巴哈纳斯必拉 & $\begin{array}{c}\text { west } \\
41-42\end{array}$ & F. Bakhanas & Бақанас/Bakanas \\
\hline 145. & E'erkebuqi bila 额尔克布齐必拉 & $\begin{array}{c}\text { west } \\
40-41\end{array}$ & F. Ergheboutsi & \\
\hline 146. & Alaketu'a 阿拉克图阿 & $\begin{array}{c}\text { west } \\
40-41\end{array}$ & M. Alaktou & \\
\hline 147. & Ba'erkaxi nao'er 巴尔喀锡淖尔 & $\begin{array}{c}\text { west } \\
40-41\end{array}$ & $\begin{array}{l}\text { L. Balkassi- } \\
\text { noor }\end{array}$ & Балқаш/Balksh \\
\hline 148. & Cha'er bila 察尔必拉 & $\begin{array}{c}\text { west } \\
39-40\end{array}$ & F. Tsar & \\
\hline 149. & Cha'er bila 察尔必拉 & $\begin{array}{c}\text { west } \\
40-41\end{array}$ & F. Tsar & \\
\hline 150. & Cha'er bila 察尔必拉 & $\begin{array}{c}\text { west } \\
41-42\end{array}$ & F. Tsar & $\begin{array}{l}\text { Char Gurban [41, } \\
\text { T. VII, p. 24] }\end{array}$ \\
\hline 151. & Amanha'erhai 阿满哈尔海 & $\begin{array}{c}\text { west } \\
41-42\end{array}$ & Amankharkhai & $\begin{array}{c}\text { Амақарағай/ } \\
\text { Amanqaraghay }\end{array}$ \\
\hline 152. & $\begin{array}{l}\text { Xidete Eleimo alin } \\
\text { 锡德特额壘谟阿林 }\end{array}$ & $\begin{array}{c}\text { west } \\
42-43\end{array}$ & $\begin{array}{l}\text { M. Sidet- } \\
\text { elouimo }\end{array}$ & $\begin{array}{c}\text { Ереймен/Ereimen } \\
\text { Ereimen Schidor in the } \\
\text { Renat map [56, p. } 686 \text {; } \\
\text { 7, p. cciv] }\end{array}$ \\
\hline
\end{tabular}




\begin{tabular}{|c|c|c|c|c|}
\hline 153. & Bayan alin 巴彦阿林 & $\begin{array}{c}\text { west } \\
41-42\end{array}$ & Bayanaula & $\begin{array}{c}\text { Bayan-Ola [56, p. 645; } \\
\text { 50, IV, p. 117] }\end{array}$ \\
\hline \multicolumn{5}{|c|}{ Sixth rows west 4 六排西四 } \\
\hline 154. & Wenggun alin 瓮衷阿林 & $\begin{array}{l}\text { west } \\
43-44\end{array}$ & M. Ongoun & \\
\hline 155. & $\begin{array}{c}\text { Hu'erha'erjin } \\
\text { nao'er胡尔哈尔金淖尔 }\end{array}$ & $\begin{array}{c}\text { west } \\
44-45\end{array}$ & $\begin{array}{c}\text { F. } \\
\text { Khourkhaldsin }\end{array}$ & $\begin{array}{c}\text { Қорғалжын (көл)/ } \\
\text { Korgalžyn }\end{array}$ \\
\hline 156. & Nula bila 努拉必拉 & $\begin{array}{c}\text { west } \\
44-45\end{array}$ & F. Noura & Hұpa/Nura \\
\hline 157. & Yisete emo 伊色特鄂谟 & $\begin{array}{c}\text { west } \\
47-48 \\
\end{array}$ & L. Isset & \\
\hline 158. & Miyasi emo 米阿斯鄂谟 & $\begin{array}{c}\text { west } \\
47-48\end{array}$ & L. Miass & $\begin{array}{l}\text { Миасc/Miass [41, } \\
\text { T. VI, p. 312] }\end{array}$ \\
\hline 159. & Halaguote'er 哈拉郭特尔 & $\begin{array}{c}\text { west } \\
47-48\end{array}$ & F. Khara-gochir & \\
\hline 160. & Eleke bila 额勒克必拉 & $\begin{array}{c}\text { west } \\
47-48\end{array}$ & F. Elek & \\
\hline 161. & Wula'ertu alin 乌拉尔图阿林 & $\begin{array}{c}\text { west } \\
48-49\end{array}$ & M. Oural tou & \\
\hline 162. & Kukuguote'er 库库郭特尔 & $\begin{array}{c}\text { west } \\
48-49\end{array}$ & Koukou-goter & \\
\hline 163. & Chahan bila 察罕必拉 & $\begin{array}{c}\text { west } \\
48-49\end{array}$ & F. Tsakhan & \\
\hline 164. & Taqi hetun 塔奇和屯 & $\begin{array}{c}\text { west } \\
48-49\end{array}$ & Taki & $\begin{array}{l}\text { Орал/Ural in Kazakh- } \\
\text { stan [41, T. VI, p. 220] }\end{array}$ \\
\hline 165. & Gashun 噶顺 & $\begin{array}{l}\text { west } \\
49-50\end{array}$ & Gachun & Гашон/Gashon \\
\hline 166. & De'erteke'er alin 德尔特科尔阿林 & $\begin{array}{c}\text { west } \\
50-51\end{array}$ & M. Derdekor & \\
\hline 167. & Ebo hetun 鄂傅和屯 & $\begin{array}{c}\text { west } \\
51-52\end{array}$ & Ofou (ville) & Уфа/Ufa \\
\hline 168. & Saladuofu hetun 萨拉多傅和屯 & $\begin{array}{c}\text { west } \\
53-54 \\
\end{array}$ & Siratow (ville) & Саратов/Saratov \\
\hline 169. & Ha’ermisi 哈尔密斯 & $\begin{array}{l}\text { west } \\
58-59\end{array}$ & & $\begin{array}{c}\text { Qārmish } \\
\text { (Карамышево?) }\end{array}$ \\
\hline 170. & Yi’errisi bila 伊尔日斯必拉 & $\begin{array}{c}\text { west } \\
53-54\end{array}$ & F. Yrjich & $\begin{array}{c}\text { (Большой) Иргиз/ } \\
\text { Irgiz River }\end{array}$ \\
\hline 171. & Galamen bila 噶拉扪必拉 & $\begin{array}{c}\text { west } \\
52-53\end{array}$ & F. Galamun & $\begin{array}{c}\text { Karaman [41, T. VI, } \\
\text { p. 113] }\end{array}$ \\
\hline 172. & Wo’erga bila 倭尔噶必拉 & $\begin{array}{l}\text { west } \\
54-55\end{array}$ & F. Wolga & Волга/Volga \\
\hline 173. & $\begin{array}{l}\text { Xilahamisi hetun } \\
\text { 锡拉哈米斯和屯 }\end{array}$ & $\begin{array}{c}\text { west } \\
55-56\end{array}$ & $\begin{array}{c}\text { Sherkamish* } \\
\text { [43, T. VI, } \\
\text { p. 120] }\end{array}$ & Камыши/Kamyshin \\
\hline
\end{tabular}




\begin{tabular}{|c|c|c|c|c|}
\hline 174. & Teng 滕 & $\begin{array}{c}\text { west } \\
57-58\end{array}$ & Don* & Дон/Don \\
\hline 175. & Manacha 玛纳察 & $\begin{array}{c}\text { west } \\
57-58\end{array}$ & Manacha* & Manych [28, p. 52] \\
\hline \multicolumn{5}{|c|}{ Sixth rows west 5 六排西五 } \\
\hline 176. & Hala Tengjisi 哈拉腾吉斯 & $\begin{array}{l}\text { west } \\
65-66\end{array}$ & Qara Tengiz* & Black Sea \\
\hline 177. & $\begin{array}{l}\text { Yisitanba'er hetun Kongka'er juchu } \\
\text { 伊斯坦巴尔和屯控喀尔居处 }\end{array}$ & $\begin{array}{c}\text { west } \\
66-67\end{array}$ & & Istanbul \\
\hline \multicolumn{5}{|c|}{ Seventh rows west 3 七排西三 } \\
\hline 178. & Nalin bila 纳林必拉 & $\begin{array}{c}\text { west } \\
33-34\end{array}$ & Narym & \\
\hline 179. & Sali alin 萨里阿林 & $\begin{array}{c}\text { west } \\
31-32\end{array}$ & M. Sari & Cayp/Saur \\
\hline 180. & $\begin{array}{l}\text { Hetongha'erhai kalun } \\
\text { 和通哈尔海喀论 }\end{array}$ & $\begin{array}{c}\text { west } \\
33-34\end{array}$ & $\begin{array}{l}\text { Khotongkarkha } \\
\text { i-Kharaoul }\end{array}$ & $\begin{array}{l}\text { Қатынқарағай/ } \\
\text { Katonkaragay }\end{array}$ \\
\hline 181. & Zaisang nao’er 斋桑淖尔 & $\begin{array}{c}\text { west } \\
32-33\end{array}$ & $\begin{array}{l}\text { L. Dsaisang- } \\
\text { noor }\end{array}$ & Зайсан/Zaysan \\
\hline 182. & Edong bila 鄂东必拉 & $\begin{array}{c}\text { west } \\
32-33\end{array}$ & F. Etoung & Үйдене/Üydene \\
\hline 183. & $\begin{array}{l}\text { Temu'erchuo'erhe alin } \\
\text { 特穆尔绰尔和阿林 }\end{array}$ & $\begin{array}{c}\text { west } \\
32-33\end{array}$ & $\begin{array}{l}\text { M. Tomour- } \\
\text { dchor }\end{array}$ & \\
\hline 184. & $\begin{array}{l}\text { Temu'erchuo'erhe bila } \\
\text { 特穆尔绰尔和必拉 }\end{array}$ & $\begin{array}{c}\text { west } \\
32-33\end{array}$ & $\begin{array}{l}\text { F. Temour- } \\
\text { Tchorkho }\end{array}$ & $\begin{array}{c}\text { Қандысу- } \\
\text { Шорға/Qandysu- } \\
\text { Shorgha }\end{array}$ \\
\hline 185. & $\begin{array}{l}\text { E'erhechuo'er alin } \\
\text { 鄂尔和绰尔阿林 }\end{array}$ & $\begin{array}{c}\text { west } \\
32-33\end{array}$ & $\begin{array}{c}\text { M. } \\
\text { Orkchodchor }\end{array}$ & Орқашар/Orqashar \\
\hline 186. & Ha'erba alin 哈尔巴阿林 & $\begin{array}{c}\text { west } \\
34-35\end{array}$ & M.Khalba & Қалба жотасы/ Qalba \\
\hline 187. & Kebukuketu alin 科布库克图阿林 & $\begin{array}{c}\text { west } \\
34-35\end{array}$ & $\begin{array}{c}\text { M. } \\
\text { Kobkouktou }\end{array}$ & Көкпекті /Kokpekty \\
\hline 188. & $\begin{array}{l}\text { Abuta'ermoduo kalun } \\
\text { 阿布塔尔谟多喀伦 }\end{array}$ & $\begin{array}{c}\text { west } \\
33-34\end{array}$ & $\begin{array}{l}\text { Abtalmodo } \\
\text { Kharaoul }\end{array}$ & \\
\hline 189. & $\begin{array}{l}\text { Abuta'ermoduo bila } \\
\text { 阿布塔尔谟多必拉 }\end{array}$ & $\begin{array}{c}\text { west } \\
33-34\end{array}$ & F. Abtalmodo & \\
\hline 190. & Boluonai alin 博罗舅阿林 & $\begin{array}{c}\text { west } \\
34-35\end{array}$ & Boronai & \\
\hline 191. & Ha'erba dabahan 哈尔巴达巴汉 & $\begin{array}{c}\text { west } \\
34-35\end{array}$ & $\begin{array}{l}\text { M. Khalba } \\
\text { dabakhan }\end{array}$ & Қалба жотасы/ Qalba \\
\hline 192. & Kuliyetu 库里野图 & $\begin{array}{c}\text { west } \\
35-36\end{array}$ & Kourietou & \\
\hline 193. & Bukun bila 布坤必拉 & $\begin{array}{c}\text { west } \\
34-35\end{array}$ & F. Bougoun & $\begin{array}{l}\text { Букен/Buken [ } 41 \text {, } \\
\text { T. VII, p. 25] }\end{array}$ \\
\hline
\end{tabular}




\begin{tabular}{|c|c|c|c|c|}
\hline 194. & Ta'erbahatai alin 塔尔巴哈台阿林 & $\begin{array}{c}\text { west } \\
34-35\end{array}$ & M. Tarbakhatai & Тарбағатай/Tarbagatay \\
\hline 195. & Baketu alin 巴克图阿林 & $\begin{array}{c}\text { west } \\
34-35\end{array}$ & M. Baktou & Бақты/Bakty \\
\hline 196. & Baketu kalun 巴克图咯伦 & $\begin{array}{c}\text { west } \\
33-34\end{array}$ & $\begin{array}{l}\text { Baktou- } \\
\text { Kharaoul }\end{array}$ & Бақты/Bakty \\
\hline 197. & Hama'er dabahan 哈玛尔达巴汉 & $\begin{array}{l}\text { west } \\
33-34\end{array}$ & $\begin{array}{l}\text { M. Khamar } \\
\text { dabakhan }\end{array}$ & Хамар асуы/Khamar \\
\hline 198. & $\begin{array}{l}\text { Jimo’ersike kalun } \\
\text { 集谟尔斯克咯伦 }\end{array}$ & $\begin{array}{c}\text { west } \\
33-34\end{array}$ & $\begin{array}{l}\text { Dsimorsek } \\
\text { Kharaoul }\end{array}$ & Жимерсек/Jimersek \\
\hline 199. & $\begin{array}{l}\text { Wunahen Tuoluohui } \\
\text { 乌讷狠托罗辉 }\end{array}$ & $\begin{array}{c}\text { west } \\
33-34\end{array}$ & & $\begin{array}{c}\text { Кунехен- } \\
\text { Толохай/Kunekhen- } \\
\text { Tolokhay }\end{array}$ \\
\hline 200. & Zhuluhuzhu bila 珠鲁胡珠必拉 & $\begin{array}{c}\text { west } \\
32-33\end{array}$ & $\begin{array}{l}\text { F. Dchourou- } \\
\text { khoudchou }\end{array}$ & Жур-хужу/Zhur-khuzhu \\
\hline 201. & Zhuluhuzhu kalun 珠鲁胡珠喀伦 & $\begin{array}{c}\text { west } \\
32-33\end{array}$ & $\begin{array}{l}\text { Dchourou- } \\
\text { khoudchou } \\
\text { Kharaoul }\end{array}$ & Жур-хужу/Zhur-khuzhu \\
\hline 202. & Yu'er bila 玉尔必拉 & $\begin{array}{l}\text { west } \\
34-35\end{array}$ & F. Yur & Юp/Yur \\
\hline 203. & Ya'er bila 雅尔必拉 & $\begin{array}{c}\text { west } \\
34-35\end{array}$ & F. Yar & Яp/Yar \\
\hline 204. & $\begin{array}{l}\text { Alaketuhu'er nao'er } \\
\text { 阿拉克图胡尔淖尔 }\end{array}$ & $\begin{array}{c}\text { west } \\
34-35\end{array}$ & $\begin{array}{l}\text { Alaq-Tughul } \\
\text { nor [24, I, } \\
\text { p. } 401 ; 41, \\
\text { T. VII, p. } 40]\end{array}$ & Алакөл/Alakol \\
\hline 205. & $\begin{array}{l}\text { Wenduketai A'ershan } \\
\text { 温都克台阿尔善 }\end{array}$ & $\begin{array}{c}\text { west } \\
34-35\end{array}$ & $\begin{array}{l}\text { Oundouktai } \\
\text { archan }\end{array}$ & Ундуктай/Unduktay \\
\hline 206. & Shaba'ertu Helai 沙巴尔图和赖 & $\begin{array}{c}\text { west } \\
35-36\end{array}$ & $\begin{array}{l}\text { Shabartou- } \\
\text { Kholai }\end{array}$ & Шабарты/Shabarty \\
\hline 207. & Emi’er bila 额密尔必拉 & $\begin{array}{l}\text { west } \\
34-35\end{array}$ & F. Emil & Еміл/Emil \\
\hline 208. & Katun bila 喀屯必拉 & $\begin{array}{c}\text { west } \\
34-35\end{array}$ & F. Khatoun & Қатынсу/Qatynsu \\
\hline 209. & Yamatu bila 雅玛图必拉 & $\begin{array}{c}\text { west } \\
34-35\end{array}$ & F. Yamatou & Жаманты/Zhamanty \\
\hline 210. & Ya'erhatu bila 雅尔哈图必拉 & $\begin{array}{c}\text { west } \\
34-35\end{array}$ & F. Yarkhatou & Ырғайты/Yrghayty \\
\hline 211. & A'ergalingtu 阿尔噶灵图 & $\begin{array}{c}\text { west } \\
35-36\end{array}$ & Argalingtou & $\begin{array}{c}\text { Арғанаты/Arghanaty } \\
{[56, \text { p. 148-149] }}\end{array}$ \\
\hline 212. & Abulai Hasake 阿布赖哈萨克 & $\begin{array}{c}\text { west } \\
37-38\end{array}$ & Ablai-Khassak & \\
\hline 213. & A'erhui alin 阿尔辉阿林 & $\begin{array}{c}\text { west } \\
36-37\end{array}$ & M. Arkhouy & Арқат/Arqat [43, p. 61] \\
\hline
\end{tabular}




\begin{tabular}{|c|c|c|c|c|}
\hline 214. & $\begin{array}{c}\text { Chahan buhutu } \\
\text { alin察漢布胡圖阿林 }\end{array}$ & $\begin{array}{c}\text { west } \\
35-36\end{array}$ & $\begin{array}{l}\text { M. Tsakhan- } \\
\text { boukhoutou }\end{array}$ & \\
\hline 215. & $\begin{array}{l}\text { E'erkebuqi gatu'erga } \\
\text { 額爾克布齊噶圖爾噶 }\end{array}$ & $\begin{array}{c}\text { west } \\
36-37\end{array}$ & $\begin{array}{l}\text { Erkebtsi- } \\
\text { gatulga }\end{array}$ & \\
\hline 216. & Agusi 阿古斯 & $\begin{array}{c}\text { west } \\
35-36\end{array}$ & Agous & Аягөз/Ayagoz \\
\hline 217. & Aitangsu 蔼塘苏 & $\begin{array}{c}\text { west } \\
35-36\end{array}$ & R. Aitangsou & Айтаңсу/Aytangsu \\
\hline 218. & Zhaomoduo 诏谟多 & $\begin{array}{c}\text { west } \\
36-37\end{array}$ & Dchaomodo & $\begin{array}{c}\text { Жао-Модо/Zhaomodo } \\
\text { in Eastern Kazakhstan. } \\
\text { According to Humboldt, } \\
\text { Zhaomodo means } \\
\text { "Hundred Trees" in } \\
\text { Mongol. The Kazakh } \\
\text { name Jüz-aghash also } \\
\text { means "Hundred Trees" } \\
\text { [24, II, p. 224] }\end{array}$ \\
\hline 219. & Chahan tuohui 察汉托辉 & $\begin{array}{c}\text { west } \\
36-37\end{array}$ & & $\begin{array}{c}\text { Шаған-Тоғай/ } \\
\text { Shaghan-Toghay }\end{array}$ \\
\hline 220. & Heluosi bila 和罗斯必拉 & $\begin{array}{c}\text { west } \\
36-37\end{array}$ & F. Khoross & \\
\hline 221. & Bahanasi bila 巴哈纳斯必拉 & $\begin{array}{c}\text { west } \\
36-37\end{array}$ & F. Bakhanass & Бақанас/Bakanas \\
\hline 222. & Kukusa'er bila 库库萨尔必拉 & $\begin{array}{c}\text { west } \\
36-37\end{array}$ & F. Koukou ssar & \\
\hline 223. & Chahan tuohui 察罕托辉 & $\begin{array}{c}\text { west } \\
36-37\end{array}$ & $\begin{array}{l}\text { Tsakhan- } \\
\text { tokhoui }\end{array}$ & \\
\hline 224. & Lebushi bila 勒布什必拉 & $\begin{array}{c}\text { west } \\
36-37\end{array}$ & F. Lebchi & Лепсі/Lepsi \\
\hline 225. & Huchake alin 胡察克阿林 & $\begin{array}{c}\text { west } \\
36-37\end{array}$ & M. Khoudchak & \\
\hline 226. & $\begin{array}{c}\text { Kukutuomu dabahan } \\
\text { 库库托穆达巴汉 }\end{array}$ & $\begin{array}{c}\text { west } \\
35-36\end{array}$ & & Көктұма/Koktuma \\
\hline 227. & Jinjilike dabahan 金集里克达巴汉 & $\begin{array}{c}\text { west } \\
35-36\end{array}$ & & \\
\hline 228. & Bicha bila 必釷必拉 & $\begin{array}{c}\text { west } \\
34-35\end{array}$ & F. Bidcha & \\
\hline 229. & Jinjilike bila 金集里克必拉 & $\begin{array}{c}\text { west } \\
34-35\end{array}$ & F. Ghintsirik & Жүнжүрек/Zhunzhurek \\
\hline 230. & Lebuse xiqin 勒布色锡钦 & $\begin{array}{c}\text { west } \\
35-36\end{array}$ & $\begin{array}{l}\text { Source du } \\
\text { Lebchi }\end{array}$ & Lebsi sekiyen \\
\hline 231. & Bashigan bila 巴什干必拉 & $\begin{array}{c}\text { west } \\
35-36\end{array}$ & F. Bachkhan & Басқан/Baskan \\
\hline 232. & Sha'ergan bila 沙尔干必拉 & $\begin{array}{c}\text { west } \\
35-36\end{array}$ & F. Scharkan & Сарқан/Sarkan \\
\hline
\end{tabular}




\begin{tabular}{|c|c|c|c|c|}
\hline 233. & Chahan Wusu 察汉乌苏 & $\begin{array}{c}\text { west } \\
35-36\end{array}$ & $\begin{array}{l}\text { F. Tsakhan- } \\
\text { oussou }\end{array}$ & $\begin{array}{c}\text { Чаған-усу/Chaghan-usu } \\
\text { Ақсу/Aqsu [24, II, } \\
\text { p. 224] }\end{array}$ \\
\hline 234. & Bomu Wusu 博穆乌苏 & $\begin{array}{c}\text { west } \\
35-36\end{array}$ & $\begin{array}{l}\text { F. Boumou- } \\
\text { oussou }\end{array}$ & Бум-усу \\
\hline 235. & Halazhekede bila 哈拉哲克德必拉 & $\begin{array}{c}\text { west } \\
36-37\end{array}$ & $\begin{array}{l}\text { F. Khara } \\
\text { Dchikte }\end{array}$ & $\begin{array}{c}\text { Қаражиде/Qarajide } \\
{[56, \text { p. 198] }}\end{array}$ \\
\hline 236. & Halata'er bila 哈拉塔尔必拉 & $\begin{array}{c}\text { west } \\
37-38\end{array}$ & F. Kharatal & Қаратал/Qaratal \\
\hline 237. & Talan Huduke 塔兰胡都克 & $\begin{array}{c}\text { west } \\
37-38\end{array}$ & Talan Khuduk & \\
\hline 238. & Wulan E'erji 乌兰额尔吉 & $\begin{array}{c}\text { west } \\
37-38\end{array}$ & Oulan-erghi & Ұлан-Epxe/Ulan-Erkhe \\
\hline 239. & Qichenhala 齐陈哈拉 & $\begin{array}{c}\text { west } \\
36-37\end{array}$ & Tsitchin-khara & Шыжың/Shyjyng \\
\hline 240. & Modeyinwuhua 谟德因乌花 & $\begin{array}{c}\text { west } \\
37-38\end{array}$ & $\begin{array}{l}\text { Motein- } \\
\text { oukhoua }\end{array}$ & \\
\hline 241. & Ba’erkashi nao'e 巴尔喀什淖尔 & $\begin{array}{c}\text { west } \\
38-39\end{array}$ & Balkhach-noor & Балқаш/Balqash \\
\hline 242. & Alaketu alin 阿拉克图阿林 & $\begin{array}{c}\text { west } \\
38-39 \\
\end{array}$ & M. Alaktou & Алатау/Alatau \\
\hline 243. & Talan Huduke 塔兰胡都克 & $\begin{array}{c}\text { west } \\
37-38\end{array}$ & Talan Khuduk* & \\
\hline 244. & Guobi 郭必 & $\begin{array}{c}\text { west } \\
40-41\end{array}$ & Gobi & \\
\hline \multicolumn{5}{|c|}{ Seventh rows west 4 七排西四 } \\
\hline 245. & Han alin 汉阿林 & $\begin{array}{c}\text { west } \\
42-43\end{array}$ & M. Khan & Хан тауы/Khan tau \\
\hline 246. & $\begin{array}{l}\text { Gu'erban Hasuluke alin } \\
\text { 古尔班哈苏鲁克阿林 }\end{array}$ & $\begin{array}{l}\text { west } \\
43-44\end{array}$ & $\begin{array}{l}\text { M. Gourban } \\
\text { khaslouk }\end{array}$ & $\begin{array}{c}\text { Үш Қазылық/Üsh } \\
\text { Qazylyq [50, IV, p.117] }\end{array}$ \\
\hline 247. & Zanbula alin 䙃布拉阿林 & $\begin{array}{c}\text { west } \\
43-44\end{array}$ & M. Dsengboula & Жамбыл/Zhambyl \\
\hline 248. & Huma bila 胡玛必拉 & $\begin{array}{c}\text { west } \\
44-45\end{array}$ & F. Khouma & Құмақ/Khuma/Qumaq \\
\hline 249. & Beile gu'er 贝勒古尔 & $\begin{array}{c}\text { west } \\
44-45\end{array}$ & $\begin{array}{l}\text { Lac Beile-noor } \\
\text { ou Khochi koul }\end{array}$ & $\begin{array}{c}\text { Билікөл/Beile-gul/ } \\
\text { Peile noor. } \\
\text { Also called Qabanqulaq } \\
\text { or Khoschi-gul } \\
\text { [24, II, p. 260] }\end{array}$ \\
\hline 250. & Guobi 郭必 & $\begin{array}{c}\text { west } \\
44-45 \\
\end{array}$ & Gobi & \\
\hline 251. & Yilakeluo bila 伊拉克罗必拉 & $\begin{array}{c}\text { west } \\
45-46 \\
\end{array}$ & F. Yroklo & \\
\hline 252. & Bei Hasake 北哈萨克 & $\begin{array}{c}\text { west } \\
44-45\end{array}$ & & $\begin{array}{l}\text { "Northern Kazakh" in } \\
\text { Chinese }\end{array}$ \\
\hline
\end{tabular}




\begin{tabular}{|c|c|c|c|c|}
\hline 253. & Ama'er ji Hasake 阿玛尔吉哈萨克 & $\begin{array}{c}\text { west } \\
45-46\end{array}$ & Amargi Hasak* & $\begin{array}{c}\text { "Northern Kazakh" in } \\
\text { Manchu }\end{array}$ \\
\hline 254. & $\begin{array}{l}\text { Guqingu'erban Tuoluohui } \\
\text { 古沁古尔班托罗辉 }\end{array}$ & $\begin{array}{c}\text { west } \\
45-46\end{array}$ & $\begin{array}{c}\text { M. } \\
\text { Goutsingour- } \\
\text { ban Tolokhai } \\
\text { ou } \\
\text { Les trente trois } \\
\text { collines }\end{array}$ & $\begin{array}{c}\text { Толағай/Tolaghay } \\
{[56, \text { p. 461] }}\end{array}$ \\
\hline 255. & $\begin{array}{l}\text { Akesaha'er Ba'erbei } \\
\text { 阿克萨哈尔巴尔贝 }\end{array}$ & $\begin{array}{c}\text { west } \\
45-46\end{array}$ & $\begin{array}{l}\text { Akssakhar } \\
\text { Barbai }\end{array}$ & $\begin{array}{c}\text { Ақсақал Бар- } \\
\text { бы/Aqsaqal Barby } \\
\text { [41, T. VII, p. 41] }\end{array}$ \\
\hline 256. & $\begin{array}{l}\text { Xihe'erlike nao'er } \\
\text { 锡河尔里克淖尔 }\end{array}$ & $\begin{array}{c}\text { west } \\
45-46\end{array}$ & L. Sikhorlik & $\begin{array}{c}\text { Sikirlik [7, Renat Map, } \\
\text { no. 34] }\end{array}$ \\
\hline 257. & Seyiku bila 色衣库必拉 & $\begin{array}{c}\text { west } \\
46-47\end{array}$ & F. Seïkou & $\begin{array}{l}\text { Seiku [3, p. } 181 \text { (text), } \\
\text { p. } 191 \text { (trans.); 47, } \\
\text { Türkili Haritasi] }\end{array}$ \\
\hline 258. & Shunguo'erlu bila 顺郭尔鲁必拉 & $\begin{array}{c}\text { west } \\
47-48\end{array}$ & F. Schungorlou & $\begin{array}{c}\text { Шыңғырлау } \\
\text { /Shynggyrlau } \\
\text { [28, p. 69; 56, p. 336] }\end{array}$ \\
\hline 259. & Suiku bila 绥库必拉 & $\begin{array}{c}\text { west } \\
47-48\end{array}$ & Suoikou & \\
\hline 260. & Gegen bila 格根必拉 & $\begin{array}{c}\text { west } \\
47-48\end{array}$ & F. Keghen & \\
\hline 261. & Ya’erkasi 雅尔喀斯 & $\begin{array}{c}\text { west } \\
47-48\end{array}$ & & $\begin{array}{c}\text { Сағыз/Saygis,Sakis } \\
\text { [41, T. VII, p. 44] } \\
\text { Alternatively, an error } \\
\text { for Yrghyz [56, p. 132] }\end{array}$ \\
\hline 262. & Yinde'er alin 因德尔阿林 & $\begin{array}{c}\text { west } \\
48-49\end{array}$ & M. Yender & $\begin{array}{c}\text { Индер/Inder [28, p. } 70 ; \\
56, \text { p. 270; 41, T. VII, } \\
\text { p. 37] }\end{array}$ \\
\hline 263. & Eyi’er 鄂伊尔 & $\begin{array}{c}\text { west } \\
48-49\end{array}$ & Oir & $\begin{array}{c}\text { Ойыл/ Oiyl [28, p. 69; } \\
\text { 56, p. 116] }\end{array}$ \\
\hline 264. & Qi'er 奇尔 & $\begin{array}{c}\text { west } \\
48-49\end{array}$ & Gir & Қиыл/Qiyil [56, p. 106] \\
\hline 265. & Dapoxun nao'er 达珀逊淖尔 & $\begin{array}{c}\text { west } \\
48-49\end{array}$ & Lac de Sel & $\begin{array}{c}\text { Индер көлі/Inder köli; } \\
\text { Diuder-Tuz, Tuzdykul } \\
\text { [41, T. VII, p. 41] }\end{array}$ \\
\hline 266. & Temu'er bila 特穆尔必拉 & $\begin{array}{c}\text { west } \\
48-49\end{array}$ & Temir* & $\begin{array}{l}\text { Темір/Temir }[41, \text { T. VII, } \\
\text { p. } 45 ; 56, \text { p. } 124]\end{array}$ \\
\hline 267. & $\begin{array}{l}\text { Muhu'ertuo'er alin } \\
\text { 穆呼尔托尔阿林 }\end{array}$ & $\begin{array}{c}\text { west } \\
48-49\end{array}$ & Mughalzhar* & $\begin{array}{c}\text { Мұғалжар тауы/ } \\
\text { Mugodzhar Hills } \\
\text { [56, p. 114] }\end{array}$ \\
\hline 268. & Halaku'er 哈拉库尔 & $\begin{array}{c}\text { west } \\
49-50\end{array}$ & $\begin{array}{l}\text { Qara köl* }[9, \\
\text { p. } 65 ; 28 \\
\text { p. 69] }\end{array}$ & \\
\hline
\end{tabular}




\begin{tabular}{|c|c|c|c|c|}
\hline 269. & Samu’er 萨穆尔 & $\begin{array}{l}\text { west } \\
50-51\end{array}$ & Samur* & $\begin{array}{c}\text { Қамыс-Самар } \\
\text { көлдері/Камышъ- } \\
\text { Самаръ } \\
{[41, \text { p. } 216,221]}\end{array}$ \\
\hline 270. & Heyue'er ezhun 和岳尔额准 & $\begin{array}{c}\text { west } \\
50-51\end{array}$ & Hoyir Özen* & $\begin{array}{c}\text { Perhaps Қиыл/Qiyil; } \\
\text { also see Qi’er 奇尔 } \\
\text { (above) }\end{array}$ \\
\hline 271. & Eyichuke hetun 鄂伊楚克和屯 & $\begin{array}{c}\text { west } \\
50-51\end{array}$ & $\begin{array}{l}\text { Üyshik* } \\
{[1, \text { p. } 98]}\end{array}$ & $\begin{array}{c}\text { Атыраy/Atyrau } \\
\text { Torghuts called it Узянъ } \\
\text { Балгазинъ [41, } \\
\text { T. VI, p. 219] }\end{array}$ \\
\hline 272. & Nalin elesu 纳林额勒苏 & $\begin{array}{c}\text { west } \\
51-52\end{array}$ & Naryn els* & $\begin{array}{l}\text { Els= desert in Mongoli- } \\
\text { an, Hapын/Naryn desert } \\
\text { [56, p. 277; 41, } \\
\text { T. VI, 211] }\end{array}$ \\
\hline 273. & Taben nao’er 塔奔淖尔 & $\begin{array}{l}\text { west } \\
53-54\end{array}$ & & $\begin{array}{c}\text { Taben nao'er means } \\
\text { “Five lake” in Mongoli- } \\
\text { an. Perhaps, Besköl in } \\
\text { western Kazakhstan } \\
{[56, \text { p. } 295]}\end{array}$ \\
\hline 274. & Halaku'er 哈拉库尔 & $\begin{array}{c}\text { west } \\
49-50\end{array}$ & $\begin{array}{l}\text { Qara köl [9,p. } \\
65 ; 28, \text { p. 69] }\end{array}$ & \\
\hline 275. & $\begin{array}{l}\text { Tu'ergute zhi Ayuxi han suoju zhi } \\
\text { di 圖爾古特之阿裕錫汗所居之地 }\end{array}$ & $\begin{array}{c}\text { west } \\
54-55\end{array}$ & $\begin{array}{l}\text { Ayuki Khan's } \\
\text { Torghut state }\end{array}$ & $\begin{array}{c}\text { Also called Ayuqi } \\
\text { 阿欲奇, Ayuqi } \\
\text { 阿玉奇, or Ayuqi } \\
\text { 阿玉气, Eyueqi 鄂岳奇 } \\
\text { in Chinese sources } \\
\text { (Ayuki /Öyoki, 1640- } \\
\text { 1724) }\end{array}$ \\
\hline 276. & Dabuxun nao'er 達布遜淖爾 & $\begin{array}{c}\text { west } \\
54-55\end{array}$ & & $\begin{array}{l}\text { Bogdan Dubassun } \\
\text { (Bogdo lake) [41, } \\
\text { T. VI, p. 136] }\end{array}$ \\
\hline 277. & Eji'er bila 額集爾必拉 & $\begin{array}{l}\text { west } \\
55-56\end{array}$ & Edil* & Волга/Volga \\
\hline 278. & Suo’erla gashan 索爾拉噶珊 & $\begin{array}{l}\text { west } \\
56-57\end{array}$ & & \\
\hline 279. & Zali hetun 雜里和屯 & $\begin{array}{l}\text { west } \\
56-57\end{array}$ & & \\
\hline \multicolumn{5}{|c|}{ Seventh rows west 5 七排西五 } \\
\hline 280. & $\begin{array}{l}\text { Suochikesa'er gashan } \\
\text { 索旁克薩爾噶珊 }\end{array}$ & $\begin{array}{c}\text { west } \\
57-58\end{array}$ & & \\
\hline 281. & Re'ernuoza gashan 惹爾諾雜噶珊 & $\begin{array}{l}\text { west } \\
57-58\end{array}$ & & \\
\hline 282. & Sa'er gashan 薩爾噶珊 & $\begin{array}{l}\text { west } \\
57-58\end{array}$ & & \\
\hline 283. & Gulikesan gashan 古里克三噶珊 & $\begin{array}{l}\text { west } \\
57-58\end{array}$ & & \\
\hline
\end{tabular}




\begin{tabular}{|c|c|c|c|c|}
\hline 284. & Akexi hetun 阿噶錫和屯 & $\begin{array}{c}\text { west } \\
55-56\end{array}$ & $\begin{array}{c}\text { Akish/Akash* } \\
\text { [41, T. VI, } \\
\text { p. 128] }\end{array}$ & $\begin{array}{c}\text { Волгоград/Volgagrad } \\
\text { (Tsaritsyn) }\end{array}$ \\
\hline 285. & Bukeda alin 布克達阿林 & $\begin{array}{l}\text { west } \\
55-56\end{array}$ & $\begin{array}{c}\text { Ko Bogdo*[41, } \\
\text { T. VI, p. 137] }\end{array}$ & Bogdo \\
\hline 286. & Yanggala hetun 楊噶拉和屯 & $\begin{array}{c}\text { west } \\
55-56\end{array}$ & $\begin{array}{l}\text { Yankala/Yankh } \\
\text { ala*[41, T. VI, } \\
\text { p. 137] }\end{array}$ & $\begin{array}{l}\text { Черный Яp/ } \\
\text { Chyorny Yar }\end{array}$ \\
\hline 287. & Shuo'erbo bila 朔爾博必拉 & $\begin{array}{c}\text { west } \\
56-57\end{array}$ & $\begin{array}{c}\text { Sorpa/Shorba* } \\
\text { [41, T. VI, } \\
\text { p. 134] }\end{array}$ & \\
\hline 288. & $\begin{array}{l}\text { Zhamubeiluke huizi deng juchu } \\
\text { 札穆貝魯克回子等居處 }\end{array}$ & $\begin{array}{c}\text { west } \\
55-56\end{array}$ & $\begin{array}{l}\text { Camboyluk } \\
\text { (Jamboyluk) } \\
\text { Nogais* }\end{array}$ & \\
\hline 289. & Se'erkesi hetun 色爾克斯和屯 & $\begin{array}{c}\text { west } \\
55-56\end{array}$ & Serkes* & \\
\hline 290. & Asidalahan hetun 阿斯達拉罕和屯 & $\begin{array}{c}\text { west } \\
55-56\end{array}$ & Astrakhan* & Astrakhan \\
\hline 291. & Eji'er bila 鄂集尔必拉 & $\begin{array}{c}\text { west } \\
55-56\end{array}$ & Edil* & Volga \\
\hline 292. & $\begin{array}{l}\text { Yetesan huizi deng juchu } \\
\text { 野特散回子等居处 }\end{array}$ & $\begin{array}{c}\text { west } \\
57-58\end{array}$ & Yedisan* & $\begin{array}{l}\text { Yedi uruv, Zhetiru } \\
\text { (Zhetiru in the Middle } \\
\text { Zhuz) [47, p. 166] }\end{array}$ \\
\hline 293. & Kumo bila 库墨必拉 & $\begin{array}{c}\text { west } \\
58-59\end{array}$ & Kuma* & $\begin{array}{c}\text { Kumogol } \\
{[41, \text { T. VI, p. } 88]}\end{array}$ \\
\hline 294. & $\begin{array}{c}\text { Jilei Duonatesi } \\
\text { bila集壘多訥特斯必拉 }\end{array}$ & $\begin{array}{c}\text { west } \\
59-60\end{array}$ & $\begin{array}{l}\text { Seversky } \\
\text { Donets* }\end{array}$ & \\
\hline 295. & Duan bila 端必拉 & $\begin{array}{l}\text { west } \\
60-61\end{array}$ & Don* & \\
\hline 296. & Aiduo'er bila 愛多爾必拉 & $\begin{array}{l}\text { west } \\
63-64\end{array}$ & Aydar* & $\begin{array}{c}\text { Айдар/ Aydar } \\
\text { [28, p. 38] }\end{array}$ \\
\hline 297. & Duo'er bila 多爾必拉 & $\begin{array}{c}\text { west } \\
64-65\end{array}$ & & Торь/Tor [28, p. 36] \\
\hline \multicolumn{5}{|c|}{ Seventh rows west 6 七排西六 } \\
\hline 298. & Mo’edi emo 謨額底額謨 & $\begin{array}{c}\text { west } \\
74-75\end{array}$ & & Maeotis or Māyūṭis \\
\hline 299. & Gelansa hetun 噶蘭薩和屯 & $\begin{array}{c}\text { west } \\
68-69\end{array}$ & & Kalansse \\
\hline 300. & Damen hetun 達捫和屯 & $\begin{array}{c}\text { west } \\
72-72\end{array}$ & & Тамань \\
\hline 301. & $\begin{array}{l}\text { Fodelebisongda gashan } \\
\text { 佛德勒必宋達噶柵 }\end{array}$ & $\begin{array}{l}\text { west } \\
69-70\end{array}$ & & Ațrabezunda/Trabzon \\
\hline \multicolumn{5}{|c|}{ Eighth rows west 4 八排西四 } \\
\hline 302. & Yili bila 伊犁必拉 & $\begin{array}{c}\text { west } \\
37-38\end{array}$ & F. Ily & Іле/Ili \\
\hline
\end{tabular}




\begin{tabular}{|c|c|c|c|c|}
\hline 303. & Sha'erteke 沙爾特克 & $\begin{array}{c}\text { west } \\
37-38\end{array}$ & Sardek & \\
\hline 304. & Kukuwusu 庫庫烏蘇 & $\begin{array}{c}\text { west } \\
36-37\end{array}$ & $\begin{array}{l}\text { F. Koukou- } \\
\text { oussou }\end{array}$ & Көксу/Koksu \\
\hline 305. & $\begin{array}{l}\text { Boluohaji'er dabahan } \\
\text { 博羅哈及爾達巴漢 }\end{array}$ & $\begin{array}{c}\text { west } \\
36-37\end{array}$ & $\begin{array}{l}\text { Borokhoudsir } \\
\text { dabakhan }\end{array}$ & $\begin{array}{c}\text { Боро-хожир } \\
\text { асуы/Borokhojir asuyi }\end{array}$ \\
\hline 306. & $\begin{array}{l}\text { A'ertanemo'er dabahan } \\
\text { 阿爾坦額謨爾達巴漢 }\end{array}$ & $\begin{array}{c}\text { west } \\
36-37\end{array}$ & $\begin{array}{l}\text { M. Artan-emor } \\
\text { dabakhan }\end{array}$ & Алтынемел/Altynemel \\
\hline 307. & Gu'erban Biji 古爾班必集 & & Gurban Bije & Быжы/Bizhe River \\
\hline 308. & Chalin bila 察林必拉 & $\begin{array}{c}\text { west } \\
37-38\end{array}$ & F. Tsaring & Шарын/Charyn \\
\hline 309. & Chunji kalun 椿集喀倫 & $\begin{array}{c}\text { west } \\
35-36\end{array}$ & $\begin{array}{l}\text { Tchoundsi } \\
\text { Kharaoul }\end{array}$ & Шонжы/Shonjy \\
\hline 310. & Tuoli kalun 托里喀倫 & $\begin{array}{c}\text { west } \\
35-36\end{array}$ & Toli-Kharaoul & \\
\hline 311. & $\begin{array}{l}\text { Shabu'ertuohai kalun } \\
\text { 沙布尔托海喀倫 }\end{array}$ & $\begin{array}{c}\text { west } \\
35-36\end{array}$ & $\begin{array}{l}\text { Tchabour- } \\
\text { dchechi- } \\
\text { Karaoul }\end{array}$ & \\
\hline 312. & Ha'ergagatu'erga 哈尔噶噶圖爾噶 & $\begin{array}{c}\text { west } \\
37-38\end{array}$ & $\begin{array}{l}\text { Khargagatour- } \\
\text { ga }\end{array}$ & $\begin{array}{l}\text { Khulgan gatulga } \\
{[24, \text { II, p. } 225]}\end{array}$ \\
\hline 313. & Mingbulake 明布拉克 & $\begin{array}{c}\text { west } \\
37-38\end{array}$ & Mingboulak & Мыңбұлақ/Myngbulaq \\
\hline 314. & Nalin bila 纳林必拉 & $\begin{array}{c}\text { west } \\
37-38\end{array}$ & F. Narin & Нарын/Naryn \\
\hline 315. & Tamuhan kalun 塔穆漢喀倫 & $\begin{array}{c}\text { west } \\
36-37\end{array}$ & $\begin{array}{l}\text { Tamkhan } \\
\text { Karaoul }\end{array}$ & \\
\hline 316. & Tamutalike 塔穆干塔里克 & $\begin{array}{l}\text { west } \\
36-37\end{array}$ & Tamghantarik & \\
\hline 317. & $\begin{array}{l}\text { Temu'erlike dabahan } \\
\text { 特穆尔里克達巴漢 }\end{array}$ & $\begin{array}{c}\text { west } \\
36-37\end{array}$ & M. Temourik & Темірлік/Temirlik \\
\hline 318. & $\begin{array}{l}\text { Temu'erlike kalun } \\
\text { 特穆尔里克喀伦 }\end{array}$ & $\begin{array}{c}\text { west } \\
36-37\end{array}$ & $\begin{array}{l}\text { Temourik- } \\
\text { Karaoul }\end{array}$ & \\
\hline 319. & Gegen kalun 格根喀倫 & $\begin{array}{c}\text { west } \\
36-37\end{array}$ & Geghen & Кеген/Kegen \\
\hline 320. & Gegen bila 格根必拉 & $\begin{array}{c}\text { west } \\
36-37\end{array}$ & & \\
\hline 321. & Hantengge'er alin 漢騰格尔阿林 & $\begin{array}{c}\text { west } \\
36-37\end{array}$ & $\begin{array}{c}\text { M. } \\
\text { Khantengher }\end{array}$ & $\begin{array}{c}\text { Хан Тәңірі/ Khan } \\
\text { Tengri }\end{array}$ \\
\hline 322. & Ha'erqila kalun 哈爾奇拉喀倫 & $\begin{array}{c}\text { west } \\
36-37\end{array}$ & $\begin{array}{l}\text { Kharkira- } \\
\text { Kharaoul }\end{array}$ & Қарқара/Karkara \\
\hline 323. & Ha'erqila bila 哈爾奇拉必拉 & $\begin{array}{c}\text { west } \\
36-37\end{array}$ & F. Kharkira & Қарқара/Karkara \\
\hline 324. & Tetu dabahan 特圖達巴漢 & $\begin{array}{c}\text { west } \\
36-37\end{array}$ & $\begin{array}{l}\text { M. Tem- } \\
\text { Dabakhan }\end{array}$ & \\
\hline
\end{tabular}




\begin{tabular}{|c|c|c|c|c|}
\hline 325. & Tekesi seqin 特克斯色欽 & $\begin{array}{c}\text { west } \\
36-37\end{array}$ & $\begin{array}{l}\text { Source du } \\
\text { Tekes }\end{array}$ & Tекес/Tekes \\
\hline 326. & Kunakesa'er 庫納克薩尔 & $\begin{array}{c}\text { west } \\
36-37\end{array}$ & F. Kounouksar & \\
\hline 327. & Bayanzhu'erke 巴彥珠尔克 & $\begin{array}{c}\text { west } \\
36-37\end{array}$ & Bayandchouke & \\
\hline 328. & $\begin{array}{l}\text { Habuqihai gatu'erga } \\
\text { 哈布齊海噶圖爾噶 }\end{array}$ & $\begin{array}{c}\text { west } \\
38-39\end{array}$ & $\begin{array}{l}\text { Kapchagai- } \\
\text { gatulga }\end{array}$ & Қапшағай/ Kapshagay \\
\hline 329. & Sha'erbo'er 沙爾博爾 & $\begin{array}{c}\text { west } \\
38-39\end{array}$ & F. Schabor & Сарыбел/Sarybel? \\
\hline 330. & Saleke bila 撒勒克必拉 & $\begin{array}{c}\text { west } \\
38-39\end{array}$ & F. Salek & Шелек/ Shelek \\
\hline 331. & Tu'ergen bila 圖爾根必拉 & $\begin{array}{c}\text { west } \\
38-39\end{array}$ & F. Tourghen & Түрген/Türgen \\
\hline 332. & $\begin{array}{l}\text { Gu'erban Chabuda'er bila } \\
\text { 古爾班察布達爾必拉 }\end{array}$ & $\begin{array}{c}\text { west } \\
38-39\end{array}$ & $\begin{array}{l}\text { F. Gourban- } \\
\text { tsabdar }\end{array}$ & \\
\hline 333. & Eyigun alin 鄂衣衰阿林 & $\begin{array}{c}\text { west } \\
38-39\end{array}$ & M. Oigoun & \\
\hline 334. & Yixiketu bila 伊錫克圖必拉 & $\begin{array}{c}\text { west } \\
38-39\end{array}$ & F. Issiktou & \\
\hline 335. & Asu bila 阿蘇必拉 & $\begin{array}{c}\text { west } \\
38-39\end{array}$ & F. Assou & \\
\hline 336. & Asu dabahan 阿蘇達巴漢 & $\begin{array}{c}\text { west } \\
38-39\end{array}$ & $\begin{array}{l}\text { M. Assou- } \\
\text { dabakhan }\end{array}$ & \\
\hline 337. & Ta'erga'er bila 塔爾噶爾必拉 & $\begin{array}{c}\text { west } \\
38-39\end{array}$ & F. Talgar & Талғар/Talgar \\
\hline 338. & Mo'ergensali alin 謨爾根薩里阿林 & $\begin{array}{c}\text { west } \\
39-40\end{array}$ & $\begin{array}{l}\text { M. Morghen- } \\
\text { sari }\end{array}$ & \\
\hline 339. & $\begin{array}{l}\text { Gu'erban Alimatu } \\
\text { 古爾班阿里瑪圖 }\end{array}$ & $\begin{array}{c}\text { west } \\
39-40\end{array}$ & $\begin{array}{l}\text { Gourban- } \\
\text { Arimat }\end{array}$ & Алматы/Almaty \\
\hline 340. & Hashikeleng bila 哈什克楞必拉 & $\begin{array}{c}\text { west } \\
39-40\end{array}$ & F. Khachikleng & Қаскелең/Kaskeleng \\
\hline 341. & Chama'ergan bila 察瑪爾干必拉 & $\begin{array}{c}\text { west } \\
39-40\end{array}$ & F. Tsamargu & Шамалған/Shamalgan \\
\hline 342. & Kulutu bila 庫魯圖必拉 & $\begin{array}{c}\text { west } \\
40-41\end{array}$ & F. Kourtou & Күрті/Kurti \\
\hline 343. & Hashitake bila 哈什塔克必拉 & $\begin{array}{c}\text { west } \\
40-41\end{array}$ & F. Khachtak & Қастек/Kastek \\
\hline 344. & A'ergalingtu 阿爾噶靈圖 & $\begin{array}{c}\text { west } \\
40-41\end{array}$ & Argalingtou & Арғанаты/Arghanaty \\
\hline 345. & $\begin{array}{l}\text { Hashitake dabahan } \\
\text { 哈什塔克達巴漢 }\end{array}$ & $\begin{array}{c}\text { west } \\
40-41\end{array}$ & $\begin{array}{l}\text { M. Khachtak- } \\
\text { Dabakhan }\end{array}$ & Қастек/Kastek \\
\hline 346. & $\begin{array}{l}\text { Ya'erhatu dabahan } \\
\text { 雅爾哈圖達巴漢 }\end{array}$ & $\begin{array}{c}\text { west } \\
41-42\end{array}$ & $\begin{array}{l}\text { M. Yarkhatou- } \\
\text { Dabakhan }\end{array}$ & \\
\hline
\end{tabular}




\begin{tabular}{|c|c|c|c|c|}
\hline 347. & Chui bila 吹必拉 & $\begin{array}{c}\text { west } \\
42-43\end{array}$ & F. Tchoui & Шу/Chu \\
\hline 348. & He'erhetu bila 和爾和圖必拉 & $\begin{array}{c}\text { west } \\
42-43\end{array}$ & R. Khotkhatou & $\begin{array}{c}\text { Кұрағаты/Quraghaty } \\
{[56, \text { p. 360] }}\end{array}$ \\
\hline 349. & $\begin{array}{l}\text { Gu'erban Hayintu bila } \\
\text { 古爾班哈因圖必拉 }\end{array}$ & $\begin{array}{c}\text { west } \\
42-43\end{array}$ & $\begin{array}{l}\text { F. Gourban } \\
\text { Khayntou }\end{array}$ & \\
\hline 350. & Ashaba'er bila 阿沙巴爾必拉 & $\begin{array}{c}\text { west } \\
42-43\end{array}$ & F. Khochabar & \\
\hline 351. & Botuomaitake 博托邁塔克 & $\begin{array}{c}\text { west } \\
42-43\end{array}$ & $\begin{array}{l}\text { M. Botamai- } \\
\text { tak }\end{array}$ & $\begin{array}{c}\text { Ботамойнак/Botamoy- } \\
\text { naq }[56, \text { p. } 347]\end{array}$ \\
\hline 352. & Talasi bila 塔拉斯必拉 & $\begin{array}{c}\text { west } \\
44-45\end{array}$ & F. Talas & Талас/Talas \\
\hline 353. & Ashai alin 阿笁阿林 & $\begin{array}{c}\text { west } \\
44-45\end{array}$ & M. Achai & \\
\hline 354. & Heselate alin 河色拉特阿林 & $\begin{array}{c}\text { west } \\
44-45\end{array}$ & M. Khoserat & \\
\hline 355. & Boshi'ahashimo 博什阿哈什謨 & $\begin{array}{c}\text { west } \\
44-45\end{array}$ & $\begin{array}{l}\text { Bochakhach- } \\
\text { mo }\end{array}$ & \\
\hline 356. & $\begin{array}{l}\text { Temo'erhabahake } \\
\text { 特謨爾哈巴哈克 }\end{array}$ & $\begin{array}{c}\text { west } \\
44-45\end{array}$ & $\begin{array}{c}\text { Temor- } \\
\text { khabakhak }\end{array}$ & \\
\hline 357. & Asha bila 阿沙必拉 & $\begin{array}{c}\text { west } \\
45-46\end{array}$ & F. Acha & Aca/Asa \\
\hline 358. & Agu'er nao'er 阿古爾淖尔 & $\begin{array}{c}\text { west } \\
45-46\end{array}$ & & \\
\hline 359. & Minbula 敏布拉 & $\begin{array}{c}\text { west } \\
45-46\end{array}$ & & \\
\hline 360. & Biku'er nao'er 必庫爾淖爾 & $\begin{array}{c}\text { west } \\
46-47\end{array}$ & & \\
\hline 361. & $\begin{array}{l}\text { Halaha'erbake teheba } \\
\text { 哈拉哈爾巴克特赫巴 }\end{array}$ & $\begin{array}{c}\text { west } \\
46-47\end{array}$ & $\begin{array}{c}\text { Qaraqalpaq } \\
\text { tehe ba } \\
\text { (Tehe ba means } \\
\text { "homeland" } \\
\text { in Manchu) }\end{array}$ & $\begin{array}{l}\text { Қарақалпақстан } \\
\text { /Karakalpakstan }\end{array}$ \\
\hline 362. & $\begin{array}{l}\text { Suo'ertunyi nukete } \\
\text { 索爾屯衣努克特 }\end{array}$ & $\begin{array}{c}\text { west } \\
46-47\end{array}$ & & Solto? \\
\hline 363. & $\begin{array}{l}\text { Baibisitan nukete } \\
\text { 拜必斯坦努克特 }\end{array}$ & $\begin{array}{c}\text { west } \\
47-48\end{array}$ & & \\
\hline 364. & Xi'er bila 錫爾必拉 & $\begin{array}{c}\text { west } \\
47-48\end{array}$ & & Сырдария/ Syr Darya \\
\hline 365. & Minbula 敏布拉 & $\begin{array}{c}\text { west } \\
45-46\end{array}$ & & Мыңбұлақ/Mingbulaq \\
\hline \multicolumn{5}{|c|}{ Eighth rows west 5 八排西五 } \\
\hline 366. & Haina'er bila 海納爾必拉 & $\begin{array}{l}\text { west } \\
50-51\end{array}$ & & $\begin{array}{l}\text { Қайнар/Qaynar [41, } \\
\text { T. VII, p. 45; 56, p. 100] }\end{array}$ \\
\hline
\end{tabular}




\begin{tabular}{|c|c|c|c|c|}
\hline 367. & Tashigan 塔什干 & $\begin{array}{c}\text { west } \\
48-49\end{array}$ & Tashkent* & Ташкент/Tashkent \\
\hline 368. & Zhemu bila 哲木必拉 & $\begin{array}{l}\text { west } \\
50-51\end{array}$ & Jem* & Жем (Ембі)/ Еmbа \\
\hline 369. & $\begin{array}{l}\text { Mang'axilu dabahan } \\
\text { 䒭阿錫魯達巴漢 }\end{array}$ & $\begin{array}{c}\text { west } \\
50-51\end{array}$ & $\begin{array}{l}\text { Manggishlaq } \\
\text { dabagan* }\end{array}$ & $\begin{array}{c}\text { Мангы- } \\
\text { стау/Manghystau }\end{array}$ \\
\hline 370. & $\begin{array}{l}\text { Wa'erji Hasake zhecheng } \\
\text { 瓦爾吉哈薩克哲成 }\end{array}$ & $\begin{array}{l}\text { west } \\
50-51\end{array}$ & $\begin{array}{l}\text { Wargi Hasak } \\
\text { jecen* } \\
\text { (wargi means } \\
\text { "west" in } \\
\text { Manchu) }\end{array}$ & west Qazaq border \\
\hline 371. & Halazhake 哈拉扎克 & $\begin{array}{c}\text { west } \\
53-54\end{array}$ & & \\
\hline 372. & $\begin{array}{l}\text { Halaweng'er huduke } \\
\text { 哈拉翁額爾胡都克 }\end{array}$ & $\begin{array}{c}\text { west } \\
53-54\end{array}$ & & \\
\hline 373. & $\begin{array}{l}\text { Tamangsumen huduke } \\
\text { 塔莽蘇捫胡都克 }\end{array}$ & $\begin{array}{c}\text { west } \\
53-54\end{array}$ & $\begin{array}{l}\text { L. Tapoun- } \\
\text { ssoumoun- } \\
\text { Khodouk }\end{array}$ & \\
\hline 374. & Buxun nao'er 布遜淖爾 & $\begin{array}{c}\text { west } \\
53-54\end{array}$ & Lac. Boussoun & \\
\hline 375. & $\begin{array}{l}\text { E'erheji huizi hetun } \\
\text { 鄂爾和集回子和屯 }\end{array}$ & $\begin{array}{c}\text { west } \\
54-55\end{array}$ & & \\
\hline 376. & $\begin{array}{l}\text { Tu'erkumen suoju zhidi } \\
\text { 圖爾庫捫所居之地 }\end{array}$ & $\begin{array}{c}\text { west } \\
52-53\end{array}$ & $\begin{array}{l}\text { Pays de } \\
\text { Turkmen }\end{array}$ & Туркмен/Turkmen \\
\hline 377. & $\begin{array}{l}\text { Dalintubo huduke } \\
\text { 這林圖博胡都克 }\end{array}$ & $\begin{array}{c}\text { west } \\
52-53\end{array}$ & $\begin{array}{l}\text { Source ou Lac } \\
\text { Dserin Toubo }\end{array}$ & \\
\hline 378. & Hulamaji huduke 胡拉瑪集胡都克 & $\begin{array}{c}\text { west } \\
52-53\end{array}$ & $\begin{array}{l}\text { Source ou Lac } \\
\text { Khouramadsi }\end{array}$ & \\
\hline 379. & Dabuxun nao'er 達布遜淖爾 & $\begin{array}{c}\text { west } \\
52-53\end{array}$ & Lac de Sel & \\
\hline 380. & Qiawa hetun 恰瓦和屯 & $\begin{array}{c}\text { west } \\
52-53\end{array}$ & Ywa & Хива/Khiva \\
\hline 381. & $\begin{array}{l}\text { Bokete'er huizi hetun } \\
\text { 博克特爾回子和屯 }\end{array}$ & $\begin{array}{c}\text { west } \\
51-52\end{array}$ & $\begin{array}{l}\text { Bokter ville } \\
\text { des } \\
\text { Boukhars }\end{array}$ & $\begin{array}{l}\text { On the right bank of the } \\
\text { Yaik, the name of } \\
\text { Bagthiar occurs on } \\
\text { Jenkinson's map. The } \\
\text { Bakhtiari were relocated } \\
\text { to the Turkoman frontier } \\
\text { by Nadir Shah. }\end{array}$ \\
\hline 382. & $\begin{array}{l}\text { Xilawate huizi hetun } \\
\text { 錫拉瓦特回子和屯 }\end{array}$ & $\begin{array}{c}\text { west } \\
51-52\end{array}$ & $\begin{array}{l}\text { Sirawat villes } \\
\text { des Boukhars }\end{array}$ & $\begin{array}{l}\text { A corruption of Shahri- } \\
\text { Vezir. This "castle", or } \\
\text { fortified town, of } \\
\text { Shaÿsure (Sellizure on } \\
\text { Jenkinson's } \\
\text { text) has been identified } \\
\text { with Shahr, or Shehr } \\
\text { Vezir (Shahr }\end{array}$ \\
\hline
\end{tabular}




\begin{tabular}{|c|c|c|c|c|}
\hline & & & & $\begin{array}{l}\text { signifying town), now } \\
\text { marked by the ruins of } \\
\text { Dev-Kesken, or Dev } \\
\text { Kesken qala, is an ar- } \\
\text { chaeological site in the } \\
\text { Dashoguz region of } \\
\text { northern Turkmenistan, } \\
62 \text { km west of } \\
\text { Koneurgench } \\
{[15, \text { p. 69]. }}\end{array}$ \\
\hline 383. & $\begin{array}{l}\text { Abalagazha han zhizi exianshi } \\
\text { han suoju zhidi } \\
\text { 阿巴拉噶扎漢之子額先什罕所居 } \\
\text { 之地 }\end{array}$ & $\begin{array}{c}\text { west } \\
51-52\end{array}$ & $\begin{array}{l}\text { Demeure de } \\
\text { Enouchi khan } \\
\text { fils d'Abla } \\
\text { khodcha-khan }\end{array}$ & $\begin{array}{l}\text { Ануша-хан/Anusha } \\
\text { khan (1663-1686) }\end{array}$ \\
\hline 384. & $\begin{array}{l}\text { Ala'ertuohui Esiboke deng suoju } \\
\text { 阿拉爾托輝鄂斯博克等所居 }\end{array}$ & $\begin{array}{c}\text { west } \\
50-51\end{array}$ & $\begin{array}{l}\text { Demeure de } \\
\text { chef Aral- } \\
\text { Tokhoui } \\
\text { Ossbok }\end{array}$ & $\begin{array}{l}\text { Арал Өзбектері/Aral } \\
\text { Uzbeks }[19, \text { p. 651] }\end{array}$ \\
\hline 385. & Daligang’a emo 達里崗阿鄂謨 & $\begin{array}{c}\text { west } \\
51-52\end{array}$ & Lac Daliganga & $\begin{array}{l}\text { Арал Теңізі/Aral sea } \\
\text { [=Dari-yangya] }\end{array}$ \\
\hline 386. & $\begin{array}{l}\text { Halakezi huizi hetun } \\
\text { 哈拉科子回子和屯 }\end{array}$ & $\begin{array}{c}\text { west } \\
51-52\end{array}$ & $\begin{array}{l}\text { Karakhodsu } \\
\text { ville des } \\
\text { Boukhars }\end{array}$ & $\begin{array}{l}\text { Qara-Hajji? } \\
{[19, \text { p. } 54-55]}\end{array}$ \\
\hline 387. & $\begin{array}{l}\text { Wu'ergenqi huizi hetun } \\
\text { 烏爾根齊回子和屯 }\end{array}$ & $\begin{array}{c}\text { west } \\
51-52\end{array}$ & $\begin{array}{l}\text { Ourghenz, ville } \\
\text { des Boukhars }\end{array}$ & Ургенч/Urgench \\
\hline 388. & Tengjisi emo 騰吉斯鄂謨 & $\begin{array}{c}\text { west } \\
54-55\end{array}$ & & $\begin{array}{c}\text { Теңіз/Tengiz } \\
\text { Tatars called it Chagan } \\
\text { Тengis (Чаганъ } \\
\text { Тенгисъ), Kalmyks } \\
\text { called it Kulsom Tengis } \\
\text { (Кулсомъ Тенгисъ) } \\
\text { [41, Т. VI, p. 87] }\end{array}$ \\
\hline 389. & Sama'erhan 薩瑪爾罕 & $\begin{array}{l}\text { west } \\
50-51\end{array}$ & Samarkhan & Самарканд/Samarkand \\
\hline 390. & E’ertuba 鄂爾圖巴 & $\begin{array}{c}\text { west } \\
49-50\end{array}$ & Ortouba & $\begin{array}{c}\text { Истаравшан } \\
\text { /Istarawschan } \\
\text { (Ura-Tjube) }\end{array}$ \\
\hline 391. & Hejiyan 和濟彥 & $\begin{array}{c}\text { west } \\
48-49\end{array}$ & $\begin{array}{l}\text { Khodsiyan } \\
\text { Khodchend }\end{array}$ & Худжанд/ Khujand \\
\hline 392. & $\begin{array}{l}\text { Ajige buka'er zhecheng } \\
\text { 阿濟格布喀爾哲成 }\end{array}$ & $\begin{array}{c}\text { west } \\
49-50\end{array}$ & $\begin{array}{l}\text { Ville Adsigheb- } \\
\text { chardche }\end{array}$ & $\begin{array}{l}\text { Little Bukhara border } \\
\text { [ajige means “little” } \\
\text { in Manchu, } \\
\text { “布喀尔=Bukhara;“哲 } \\
\text { 成=jecen (border)”] }\end{array}$ \\
\hline 393. & Naiman nukete 奈滿努克特 & $\begin{array}{c}\text { west } \\
48-49\end{array}$ & $\begin{array}{l}\text { Nayman- } \\
\text { Nouktè }\end{array}$ & $\begin{array}{l}\text { Найман/Nayman } \\
\text { pastoral area }\end{array}$ \\
\hline 394. & Dayate nukete 達雅特努克特 & $\begin{array}{c}\text { west } \\
47-48\end{array}$ & Tayat- Nouktè & Теит/Teyit \\
\hline
\end{tabular}




\begin{tabular}{|c|c|c|c|c|}
\hline 395. & Jibuchake alin 吉布察克阿林 & $\begin{array}{l}\text { west } \\
46-47\end{array}$ & M. Kibdchak & Қыпшақ/Qypchaq \\
\hline 396. & $\begin{array}{l}\text { Lianlabashi huizi deng juchu } \\
\text { 連拉巴斯回子等居處 }\end{array}$ & $\begin{array}{c}\text { west } \\
58-59\end{array}$ & & Mali bash \\
\hline 397. & De’erji hetun 德爾集和屯 & $\begin{array}{c}\text { west } \\
58-59\end{array}$ & Tarki* & $\begin{array}{c}\text { Тарки/Tarki } \\
\text { [the place referred to, } \\
\text { evidently Terki, is at the } \\
\text { mouth of the Terek, } \\
\text { Dagestan, 28, p. 60] }\end{array}$ \\
\hline 398. & Te'erben hetun 特爾奔和屯 & $\begin{array}{l}\text { west } \\
59-60\end{array}$ & Derbent* & Дербент/Derbent \\
\hline \multicolumn{5}{|c|}{ Eighth rows west 6 八排西六 } \\
\hline 399. & Shamaji hetun 沙馬吉和屯 & $\begin{array}{c}\text { west } \\
59-60\end{array}$ & & Shamakhi, Azerbaijan \\
\hline 400. & Gu'er bila 古爾必拉 & $\begin{array}{l}\text { west } \\
60-61\end{array}$ & Kur & Kura River \\
\hline 401. & Nashiwang bila 那什旺必拉 & $\begin{array}{l}\text { west } \\
61-62\end{array}$ & & Nakhchivan \\
\hline 402. & Eliwang hetun 額裡旺和屯 & $\begin{array}{c}\text { west } \\
62-63\end{array}$ & Erivan & Yerevan \\
\hline 403. & Alasi bila 阿拉斯必拉 & $\begin{array}{c}\text { west } \\
63-64\end{array}$ & Aras & Aras or Araxes River \\
\hline \multicolumn{5}{|c|}{ Eighth rows west 7 八排西七 } \\
\hline 404. & Sahalian modeli 薩哈連墨德里 & $\begin{array}{c}\text { west } \\
63-64\end{array}$ & $\begin{array}{c}\text { Sahaliyan } \\
\text { mederi (Black } \\
\text { Sea in Manchu) }\end{array}$ & Black Sea \\
\hline 405. & E'erselong hetun 額爾色隆和屯 & $\begin{array}{l}\text { west } \\
76-77\end{array}$ & Erserum & Erzurum \\
\hline \multicolumn{5}{|c|}{ Eighth rows west 8 八排西八 } \\
\hline 406. & $\begin{array}{c}\text { Hongga'er guo zhi han suoju } \\
\text { Gongsidangdinabole hetun } \\
\text { 紅噶爾國之汗所居拱斯當底衲伯 } \\
\text { 勒和屯 }\end{array}$ & $\begin{array}{c}\text { west } \\
80-81\end{array}$ & $\begin{array}{c}\text { The city of } \\
\text { Constantinople, } \\
\text { where } \\
\text { Khwand-kār or } \\
\text { Khunkār Khan } \\
\text { lived [3, p. } 212 \\
\text { (text), p. } 227 \\
\text { (trans.); } 38,[\mathrm{I}], \\
\text { p. } 88-89, \\
\text { n. } 258 ; 7,[\mathrm{II}], \\
\text { p. } 330]\end{array}$ & Istanbul \\
\hline 407. & Mola hetun 謨拉和屯 & $\begin{array}{c}\text { west } \\
87-88\end{array}$ & Mora & \\
\hline \multicolumn{5}{|c|}{ Ninth rows west 5 九排西五 } \\
\hline 408. & $\begin{array}{l}\text { Zhumute huizi suoju zhi buluo } \\
\text { 珠穆特回子所居之部落 }\end{array}$ & $\begin{array}{c}\text { west } \\
50-51\end{array}$ & $\begin{array}{l}\text { Horde } \\
\text { Boukhare } \\
\text { Dchoumte }\end{array}$ & $\begin{array}{l}\text { Йомуд/Yomut (Yomud) } \\
\text { Yomut or Yomud, one of } \\
\text { the Turkmen tribes lived }\end{array}$ \\
\hline
\end{tabular}




\begin{tabular}{|c|c|c|c|c|}
\hline & & & & $\begin{array}{c}\text { in Gorgan, } \\
\text { Turkmenbashi, east } \\
\text { coast of the Caspian, } \\
\text { Khiva and Dashoguz } \\
\text { [51, p. 353] }\end{array}$ \\
\hline 409. & $\begin{array}{l}\text { Wulanguma elesu } \\
\text { 烏蘭古瑪額勒蘇 }\end{array}$ & $\begin{array}{c}\text { west } \\
51-52\end{array}$ & $\begin{array}{c}\text { Dessert } \\
\text { [Wulan=Ulan } \\
\text { means "red" in } \\
\text { Mongolian } \\
\text { +guma=qum } \\
\text { ("desert" in } \\
\text { Turkic) } \\
\text { +elesu=els } \\
\text { ("sand" in } \\
\text { Mongolian)]. }\end{array}$ & Қызылқұм/Qyzylqum \\
\hline 410. & $\begin{array}{l}\text { Teke huizi zhi buluo juchu } \\
\text { 特克回子之部落居處 }\end{array}$ & $\begin{array}{c}\text { west } \\
49-50\end{array}$ & $\begin{array}{c}\text { Horde } \\
\text { Boukhare Tek }\end{array}$ & $\begin{array}{l}\text { Takka [Teke] } \\
{[51, \text { p. } 351]}\end{array}$ \\
\hline 411. & $\begin{array}{l}\text { Anbabuka'er zhecheng } \\
\text { 安巴布喀爾哲成 }\end{array}$ & $\begin{array}{c}\text { west } \\
48-49\end{array}$ & Anbabkardchè & $\begin{array}{l}\text { Anba 安巴=amba in } \\
\text { Manchu, means } \\
\text { “Great”; "Buka'er } \\
\text { 布喀尔=Bukhara; } \\
\text { “zhecheng 哲成=jecen } \\
\text { (border)". Great } \\
\text { Bukhara border" }\end{array}$ \\
\hline 412. & $\begin{array}{l}\text { Duluma huizi zhi buluo juchu } \\
\text { 都魯瑪回子之部落居處 }\end{array}$ & $\begin{array}{c}\text { west } \\
49-50\end{array}$ & $\begin{array}{c}\text { Horde } \\
\text { Boukhare } \\
\text { Doulouma }\end{array}$ & $\begin{array}{l}\text { Дурмен } \\
\text { Durman? }\end{array}$ \\
\hline 413. & $\begin{array}{l}\text { Kekelun huizi zhi buluo juchu } \\
\text { 科克倫回子之部落居處 }\end{array}$ & $\begin{array}{c}\text { west } \\
49-50\end{array}$ & $\begin{array}{l}\text { Horde } \\
\text { Boukhare } \\
\text { Kokrun }\end{array}$ & $\begin{array}{l}\text { Гоклен/Goklen. } \\
\text { The dwelling place of } \\
\text { Goklen Muslims }\end{array}$ \\
\hline 414. & $\begin{array}{l}\text { Zhanyisiba'er huizi hetun } \\
\text { 瞻伊斯巴爾回子和屯 }\end{array}$ & $\begin{array}{l}\text { west } \\
49-50\end{array}$ & $\begin{array}{l}\text { Ville Boukhare } \\
\text { Dchensozubar }\end{array}$ & $\begin{array}{l}\text { Sabzawār or Sabzevar } \\
\text { Muslims city }\end{array}$ \\
\hline 415. & $\begin{array}{l}\text { Hazha'erbashi hongmaozi deng } \\
\text { juchu 哈扎爾巴什紅帽子等居處 }\end{array}$ & $\begin{array}{c}\text { west } \\
53-54\end{array}$ & & $\begin{array}{l}\text { The dwelling place of } \\
\text { the Qyzylbash=Read } \\
\text { Heads. } \\
\text { Кизылбаш/Qyzyl-bash } \\
\text { [28, p. 71; 3, p. 211-215 } \\
\text { (trans.); 19, p. 27-29] }\end{array}$ \\
\hline 416. & $\begin{array}{l}\text { Nishai huizi zhi buluo juchu } \\
\text { 尼篩回子之部落居處 }\end{array}$ & $\begin{array}{l}\text { west } \\
49-50\end{array}$ & & $\begin{array}{l}\text { The dwelling place of } \\
\text { Nashay Muslim tribes. } \\
\text { Nashay or Nesa, a town } \\
\text { near Bagir (near mod. } \\
\text { Ashkabad) [3, p. } 226 \\
\text { (trans.); } 19, \text { p. } 31,554]\end{array}$ \\
\hline \multicolumn{5}{|c|}{ Ninth rows west 8 九排西五 } \\
\hline 417. & Du’erjia guo 都爾佳國 & $\begin{array}{c}\text { west } \\
82-83\end{array}$ & & Turkey \\
\hline
\end{tabular}


As we have seen above, the information of Qianlong neifu yutu map was obtained during the Jesuit-led survey of Qianlong period. However, the knowledge of the Aral Sea Basin, Volga valleys, Māwarā'an-nahr as well as some other areas west of the Xinjiang was based on information provided by local authorities. The western section of the Qianlong neifu yutu describes the general form of the Anatolia, Central Asia, and Siberia, Russia which stretches from Europe in the west to Xinjiang in the east; from the Russia in the north to India and the Persian Gulf in the south; and includes Persia, Badakhshan and Afghanistan.

\section{Conclusion}

Al-Idrīsī's Maps shows the creation of map images by medieval Arab geographers based on absorbing Ptolemaic geography. Influenced by the map of AlIdrīsì', the geographic gaps and blind spots of the old continent on the European map were filled, reconstructed, and connected with the new world geographic knowledge, forming a relatively complete world map.

Al-Idrīsī's Maps also affected the geographical knowledge of Yuan-Mongol Empire geographers. The Kitāb Nuzhat al-mushtāq fì ikhtirāq al-äfāq (Entertainment for He Who Longs to Travel the World), composed in 1154 by al-Idrīsī, became significant sources for the mapmakers of Kangnido, drawn in 1402. The inclusion of Dasht-i Qipchaq and the Syr Darya Basin in the Kangnido provides clear evidence that the mapmakers consulted Al-Idrīsī's accounts for their geographical information. In addition to its pretty accurate contours, the Kangnido demonstrates knowledge about three places in Dasht-i Qipchaq, and more than ten in the Syr Darya-Talas Valley.

For example, Beisa'er was probably a corruption of Bašqurt or Bāshqarūd in Arabic sources, or refers to Bulghar, a town in modern Tatarstan; Beisu 北速 relates perhaps to the al-Bayḍā', the western city of the Ātil, all derived from alIdrīsī.

At the end of the Ming and early Qing dynasties, a large amount of overseas geographic knowledge was introduced by Western missionaries entered China. Among them the most importans are Matteo Ricci's (1552-1610) "Kunyu Wanguo Quantu" (Map of the Ten Thousand Countries of the Earth, 1602), Ferdinand Verbiest's (1623-1688) "Kun Yu Quan Tu World Map" and so on. In the middle of the Qing Dynasty, the "Map of the Emperor Yongzheng's Ten Pai Emperors" (Map of the Yongzheng reign in ten fascicles) and the Qianlong neifu yutu 乾隆内府與圖 (Terrestrial map of the imperial repository of Qianlong), which were led by western missionaries and used modern cartographic techniques, enriched the geographic information of Central Asian countries and filled the gaps in contemporary European maps.

\section{REFERENCES}

1. Obdirakhmanov A. Toponomika zhəne Etimologiya [Toponymy and Etymology]. Pavlodar, 2010. 238 p. (In Kazakh)

2. 'Abd al-Qādir ibn Muhammad-Amīn. Majma' al-ansāb wa-l-ashjār. Vokhidov Sh.H. (tr.). Istoriya Kazakhstana v persidskikh istochnikakh [History of Kazakhstan in Persian Sources]. Muminov A.K., Aminov B.B. (eds). Almaty: "Dayk-Press", 2005, vol. 2. 318 p. (In Russian) 
3. Aboul-Ghâzi Béhâdour Khân. Histoire des Mongols et des Tatares. Demaisons P.I. (tr.). Amsterdam: Philo, 1970. 393 p. (In French)

4. A General History of the Turks, Moguls, and Tatars: Vulgarly Called Tartars. Together with a Description of the Countries They Inhabit. In Two Volumes. London: J. and J. Knapton, J. Darby, A. Bettesworth, F. Fayram, J. Osborn and T. Longman, J. Pemberton, C. Rivington, F. Clay, J. Batley, and Aaron Ward, 1729, vol. 1. 374 p.

5. Angliyskie puteshestvenniki v Moskovskom gosudarstve $v$ XVI veke [English Travelers in Muscovy in the sixteenth century]. Got'e Yu.V (tr.). Leningrad, 1937. 306 p. (In Russian)

6. d'Anville J.-P. Carte la plus generale et qui comprend la Chine, la Tartarie chinoise, et le Thibet (1737). National Library of Australia MAP RM 3521. Available at: https://nla.gov.au/nla.obj-232293356 (accessed 23.11.2020). (In French)

7. Baddeley J.F. Russia, Mongolia, China, Being some Record of the Relations between Them from the Beginning of the XVII th century to the Death of the Tsar Alexei Mikhailovich, A.D. 1602-1676, Rendered Mainly in the Form of Narratives Dictated or Written by the Envoys Sent by the Russian Tsars, or Their Voevodas in Siberia to the Kalmuk and Mongol Khans and Princes; and to the Emperors of China. New York: Franklin, 1919, vol. 1. $265 \mathrm{p}$.

8. Bartold V.V. Turkestan down to the Mongol Invasion. Minorsky V., Minorsky T. (tr.). New Delhi: Munshiram Manoharlam, 1992. 513 p.

9. Batys Qazaqstan Obylysynyng Taryhy [The History of the West Kazakhstan Province]. Oral, 2015. 292 p. (In Kazakh)

10. Blaeu J. Atlas Maior of 1665 "The Greatest and Finest Atlas Ever Published". Based on the Copy in the Österreichische Nationalbibliothek, Vienna. Cologne: Taschen Verlag, 2005. $511 \mathrm{p}$.

11. Cao Wanru 曹婉如et al. (eds). Zhongguo gudai ditu ji, Mingdai 明代 [An Atlas of Ancient Maps in China: The Ming Dynasty (1368-1644)]. Beijing: Wenwu, 1994. 143 p. 248 plates. (In Chinese)

12. Collins B.A. (tr.), Mohammad Hamid Alta'i (ed.). The Best Divisions for Knowledge of the Regions = Ahsan al-Taqāsìm fì Ma rifat al-Aqālìm, [by] Al-Muqaddasī. Reading: Garnet, 1994. 424 p.

13. Drevnie goroda $i$ drugie bulgarsko-tatarskie pamyatniki v Kazanskoy gubernii [Ancient Cities and Other Bulgar-Tatar Monuments in the Kazan Province]. Shpilevsky S.M (ed.). Kazan: Tipografiya Sergeya Buzukina, 2012. 585 p. (In Russian)

14. Duval P. L'Asie. Paris, 1664. Available at: https://gallica.bnf.fr/ark: /12148/btv1b8469894b (accessed 23.11.2020). (In French)

15. Early Voyages and Travels to Russia and Persia by Anthony Jenkinson and Other Englishmen, with Some Account of the First Intercourse of the English with Russia and Central Asia by Way of the Caspian Sea. Delmar Morgan E., Coote C.H. (eds). New York: B. Franklin, 1964, vol. 1. 176 p.

16. Elliot M.C. The Limits of Tartary: Manchuria in imperial and national geographies. The Journal of Asian Studies. 2000, vol. 59, no. 3, pp. 603-646.

17. Encyclopaedia of Islam. Second edition. Bearman P.J. et al. (eds). Leiden: Brill, 1954-2005.

18. Elias N. (ed.), Denison Ross E. (tr.). The Tarikh-i-Rashidi of Mirza Muhammad Haidar, Dughlat: A History of the Moghuls of Central Asia. An English Version Edited with Commentary, Notes and Map. London: Sampson Low, Marston \& Company, 1895. 535 p.

19. Firdaws al-Iqbāl, History of Khorezm. Shir Muhammad Mirab Munis, Muhammad Riza Mirab Agahi (eds), Bregel Yu. (tr.). Leiden; Boston; Köln: Brill, 1999. 718 p.

20. Fuchs W. Der Jesuiten-Atlas der Kanghsi-Zeit: seine Entstehungsgeschichte nebst Namensindices fur die Karten der Mandjurei, Mongolei, Ostturkestan und Tibet, mit 
Wiedergabe der Jesuiten-Karten in Originalgrose. Peking: Fu-Jen University, 1943. 414 p. Available at: www.loc.gov/resource/g7820m.gct00265 (accessed 23.11.2020) (In German)

21. Geographia Nubiensis, id est accuratissima totius orbis in septem climata divisi descriptio continens praesertim exactam universiae Asiae et Africae, rerumque in iis hactenus incognitarum explicationem. Paris: Typographia Hieronymi Blageart, 1619. 328 p. (In Latin)

22. Guillaume de L'Isle. Carte de Tartarie (1706). Available at: http://www.davidrumsey.com/maps4457.html (accessed 23.11.2020). (In French)

23. Hopkins J.F.P. (tr.), Levtzion N. (ed.). Corpus of Early Arabic Sources for West African History. Cambridge: Cambridge University, 1981. 492 p.

24. Humboldt A.V. Central-Asien. Untersuchungen über die Gebirgsketten und die vergleichende Klimatologie. 2 Vols. Berlin, 1844. (In German)

25. Jupp D.L.B. Determining projection and scale for maps in early atlases of China held by the National Library of Australia. The Globe: Journal of the Australian and New Zealand Map Society Inc. 2018, no. 84, pp. 1-24.

26. Karta Antonio Dzhenkinsona 1562 goda [Anthony Jenkinson's Map of 1562]. Available at: https://www.kramola.info/blogs/letopisi-proshlogo/zapadnoevropeyskie-kartyna-russkom-anton-vid-antonio-dzhenkinson (accessed 23.11.2020). (In Latin, Russian)

27. Klaproth J. von. Cartographe présumé. Asie Centrale. Available at: https://gallica.bnf.fr/ark:/12148/btv1b72002855 (accessed 23.11.2020). (In French)

28. Kniga Bol'shomu chertezhu, ili Drevnyaya karta Rossiyskogo gosudarstva, ponovlennaya v Razryade i spisannaya v knigu 1627 goda [The Book of the "Big Drawing" or Ancient Map of the Russian State Updated in Razryadny Prikaz and Copied in the Book of 1627]. St. Petersbrurg: Tipografiya RAN, 1838. 261 p. (In Russian)

29. Kramers J.H. (ed.). Opus geographicum [i. e. Kitāb Șūrat al-arḍ] auctore ibn Haukal (Abū 'l-Kāsim ibn Haukal al-Nașībì): secundum textum et imagines codicis Constantinopolitani conservati in bibliotheca antiqui Palatii $n$. 3346 cui titulus est "Liber imaginis terrae”. 2 vols. Leiden: Brill, 1938-1939 [rpt. 1967]. (In Latin)

30. Kramers J.H., Wiet G. (trs). Ibn Hauqal: Configuration de la terre (Kitāb Șūrat alard): introduction et traduction, avec index. 2 vols. Paris: Maisonneuve and Larose, 1964. (In French)

31. Kunyu wanguo quantu (Complete Geographical Map of Ten Thousand Countries), 1602. Avalable at: https://www.wdl.org/zh/item/4136/view/1/1/ (accessed 23.11.2020). (In Chinese)

32. Mercator G. Atlas sive cosmographicae meditationes de fabrica mundi et fabricati figura, 1595. Digital reproduction of the copy held at the Lessing J. Rosenwald Collection. Oakland, Calif.: Octavo, digital edition, 2000. (In Latin)

33. Miller K. (ed.). Mappae Arabicae: Arabische Welt- und Landerkarten des 9.-13. Jahrhunderts in arabischer Urschrift, lateinischer Transkription und Ubertragung in neuzeitliche Kartenskizzen. Mit einleitenden Texten. [IV:] Asia II. Nord-und Ostasien; [VI:] Idrisi-Atlas. 336 photographische Wiedergaben aller bis jetzt bekannten geographischen Tafeln in den Manuskripten des Idrisi auf 82 Lichtdruck-Tafeln. Stuttgart, 1927. iv + 96 p.; vi +82 plates. (In German)

34. Minorsky V. (tr.). Hudūd al-'Ālam, "The Regions of the World”: A Persian Geography, 372 A.H. - 982 A.D. Oxford: Oxford University, 1937. 524 p.

35. Morar. F.-S. Relocating the Qing in the global history of science: The Manchu translation of the 1603 World Map by Li Yingshi and Matteo Ricci. Isis. 2018, vol. 109, no. 4, pp. 673-694.

36. Oblectatio desiderantis in descriptione civitatum principalium et tractuum et provinciarum et insularum et urbium et plagarum mundi. Romae, 1592. (In Arabic) 
37. Ortelius A. Theatrum orbis terrarum. Antwerpen: Apud Aegid, Coppenium Diesth, 1570. 53 maps. Copy held at the Newberry Library, Chicago. (In Latin)

38. Pelliot P. Notes critiques d'histoire Kalmouke. Paris: Maisonneuve, 1960, vol. 1. 235 p. (In French)

39. Peter Heylyn. Cosmography in Four Books: Containing the Chorography and History. London, 1677.

40. Plancius P. Orbis terrarum typus de integro multis in locis emendates. Engraved by Jan van Doetecam. Amsterdam, 1594. Available at: https://www.raremaps.com/gallery /detail/69939/orbis-terrarum-typus-de-integro-multis-in-locis-emendatus-au-plancius (accessed 23.11.2020). (In Latin)

41. Polnoye sobraniye uchenykh puteshestviy po Rossii, izdavayemoye Imperatorskoyu Akademiyu Nauk, po predlezheniyu Yeya Prezidenta [Complete Collection of Scientific Travels in Russia Published by the Imperial Academy of Sciences, at the Suggestion of Its President]. St. Petersburg, 1824, vol. 6. 560 p. (In Russian)

42. Qazaqstan Tarihy, T. 2: Qazaqstan Songghy Orta Ghasyrlar Dawirinde [The History of Kazakhstan, Vol. 2: Kazakhstan during the Late Medieval Period]. Almaty: Atamura, 1998. 636 p. (In Kazakh)

43. Qurbān-'Al̄̄ Khālidī. An Islamic Biographical Dictionary of the Eastern Kazakh Steppe 1770-1912. Franke A.J., Usmanov M.A. (eds). Leiden: Brill, 2005. 179 p.

44. Smith G.R. (tr.). The Conquest of Iran (= The History of al-Tabarī [Ta'rīkh alrusul wa'l-mulūk]). New York: University of New York, 1985 [rpt. 1994]. 216 p.

45. Szykuła K. Anthony Jenkinson's unique wall map of Russia (1562) and its influence on European cartography. Belgeo. 2008, no. 3-4, pp. 325-340.

46. Szykuła K. Unexpected $16^{\text {th }}$ century Finding to Have Disappeared Just After Its Printing - Anthony Jenkinson's Map of Russia, 1562. [Sine loco]: IntechOpen 2012. 152 p.

47. Togan A.Z.V. Bugünkü Türkili (Türkistan) ve Yakın Tarihi. İstanbul: Arkadaş, İbrahim Horoz ve Güven Basımevleri, 1942-1947. 696 p. (In Turkish)

48. Tolmacheva M. The Medieval Arabic geographers and beginnings of Modern Orientalism. International Journal of Middle East Studies. 1995, vol. 27, no. 2, pp. 141-156.

49. Tynyshpayev M. Materialy $k$ istorii kirgiz-kazakskogo naroda [Materials for the History of the Kyrgyz-Kazak People]. Tashkent, 1925. 88 p. (In Russian)

50. Valikhanov Sh. Köp Tomdyq Shygharmalar Zhynaghy [Collected Works of Choqan Valikhanov in Many Volumes]. Almaty, 2010, vol. 4. 495 p. (In Kazakh)

51. Vambéry A. Travels in Central Asia. New York, 1865. 195 p.

52. Wang Qianjin 王前进 and Liu Ruofang 刘若芳(eds). Qing ting san da shi ce quan $t u j i$ 清廷三大实则全图集. Beijing: Wai wen chu ban she, 2007. 688 p. Available at: https://qingmaps.org/ (accessed 23.11.2020). (In Chinese)

53. World Map on Ptolemy's Conic Projection, 1560 by Pietro de Nobili (1560-1579). Rome: Petri de Nobilibus formis, 1560.

54. Zhang Qiong. Making the New World Their Own: Chinese Encounters with Jesuit Science in the Age of Discovery. Leiden: Brill, 2015. 435 p.

55. Zhang Qiyun [Chang Ch'i-yun] 張其昀 (ed.). Qingdai yitong ditu 清代一統地圖 [China's National Atlas of Ching Dynasty]. Qianlong 乾隆 $25^{\text {th }}$ year (1760). Taibei: Guofang yanjiuyuan, 1966 [rpt. of the facsimile edition of the original block-prints published by the National Palace Museum in 1932 under the title: Qing Qianlong neifu yutu 清乾隆内府輿圖 (Imperial atlas of the Imperial Secretariat from the Qianlong Reign)]. (In Chinese)

56. Zheringning Aty, Elingning Haty: Encyclopediyalyq Anyqtama. Almaty, 2010. 807 p. (In Kazakh) 
About the authors: Nurlan Kenzheakhmet - Ph.D. (History), Professor of the Abai Kazakh National Pedagogical University (13, Dostyk ave., 050010 Almaty, Kazakhstan). E-mail: nurlanken@hotmail.com

Alpamys Zhalghas-uly Abu - Ph.D. candidate (Arhaeology), doctorant, Faculty of History, Arhaeology and Etnology, al-Farabi Kazakh National University (71, Al-Farabi ave., 050040 Almaty, Kazakhstan). E-mail: alpamys79@gmail.com

\title{
НЕКОТОРЫЕ СРЕДНЕВЕКОВЫЕ И ПОСТЗОЛОТООРДЫНСКИЕ ГОРОДА ИТИЛЬСКОГО (ВОЛЖСКОГО) И СЫР-ДАРЬИНСКОГО БАССЕЙНОВ СОГЛАСНО АРАБСКИМ И КИТАЙСКИМ КАРТАМ
}

\author{
Нурлан Кенжеахмет ${ }^{l}$, Алпамыс Абу ${ }^{2}$ \\ ${ }^{l}$ Казахский национальный педагогический университет имени Абая \\ Алматы, Казахстан \\ nurlanken@hotmail.com \\ ${ }^{2}$ Казахский Национальный Университет им. аль-Фараби \\ Алматы, Казахстан \\ alpamys79@gmail.com
}

Цель исследования: наиболее ранние изображения городов Итильского (Волжского) и Сыр-Дарьинского бассейнов в средневековой картографии встречаются на карте Идриси (1154 г.). Постзолотоордынские города в этой области указаны на карте Дженкинсона и на «Карте десяти тысяч стран земли» (1602 г.) Маттео Риччи. В 1772 году «Карта Императорского хранилища Цяньлуна», в которой использовались современные картографические методы, обогатила географическую информацию о странах Центральной Азии и заполнила пробелы в современных европейских картах.

Материаль исследования: под влиянием карты аль-Идриси географические пробелы и слепые пятна на европейских картах были заполнены и реконструированы. Будучи основанными на новых географических знаниях мира, они сформировали относительно полную карту мира. В конце правления династии Мин и в начале династии Цин западные миссионеры, прибывшие в Китай, представили большой объем зарубежных географических знаний.

Результаты и новизна исследования: анализ арабских, европейских и китайских карт позволил оценить степень точности их сведений о постзолотоордынских городах Итильского (Волжского) и Сыр-Дарьинского бассейнов. Авторам удалось определить представления арабских, европейских и китайских географов о Центральной Азии. В частности, в данной статье были рассмотрены топонимы Итильского бассейна (включая Западную Сибирь) и казахской степи (включая прилегающие районы) на европейско-российских имперских картах и на китайских картах Цин. Исторические карты предоставляют идеальную возможность для определения графически кодированной информации о состоянии части реального мира в определенный момент времени.

Ключевые слова: карта аль-Идриси, европейские карты, «Карта Императорского хранилища Цяньлуна», Итильский бассейн, Центральная Азия, казахская степь 
Для цитирования: Kenzheakhmet N., Abu A. Some Medieval and Post-Golden Horde's Towns of the Itil (Volga) and Syr-Darya Basins According to the Arabic and Chinese Maps // Золотоордынское обозрение. 2021. Т. 9, № 3. С. 611-653. DOI: $10.22378 / 2313-6197.2021-9-3.611-653$

Сведения об авторах: Нурлан Кенжеахмет - Ph.D., профессор, Казахский национальный педагогический университет имени Абая (050010, пр. Достык, 13, Алматы, Казахстан). E-mail: nurlanken@hotmail.com

Алпамыс Жалгас-улы Абу - Ph.D. кандидат (археология), докторант, исторический факультет, Казахский Национальный Университет им. аль-Фараби (050040, пр. аль-Фараби, 71, Алматы, Казахстан). E-mail: alpamys79@gmail.com

Поступила 10.03.2021 Принята к публикаџии 28.05.2021

Опубликована 29.09.2021 